\title{
The Neolithic of Southern China-Origin, Development, and Dispersal
}

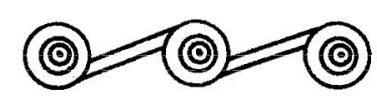

ZHANG CHI AND HSIAO-CHUN HUNG

\section{INTRODUCTION}

Sandwiched Between the Yellow River and Mainland Southeast Asia, southern China ${ }^{1}$ lies centrally within eastern Asia. This geographical area can be divided into three geomorphological terrains: the middle and lower Yangtze alluvial plain, the Lingnan (southern Nanling Mountains)-Fujian region, ${ }^{2}$ and the Yungui Plateau ${ }^{3}$ (Fig. 1). During the past 30 years, abundant archaeological discoveries have stimulated a rethinking of the role of southern China in the prehistory of China and Southeast Asia. This article aims to outline briefly the Neolithic cultural developments in the middle and lower Yangtze alluvial plain, to discuss cultural influences over adjacent regions and, most importantly, to examine the issue of southward population dispersal during this time period.

First, we give an overview of some significant prehistoric discoveries in southern China. With the discovery of Hemudu in the mid-1970s as the divide, the history of archaeology in this region can be divided into two phases. The first phase (c. 1920s-1970s) involved extensive discovery, when archaeologists unearthed Pleistocene human remains at Yuanmou, Ziyang, Liujiang, Maba, and Changyang, and Palaeolithic industries in many caves. The major Neolithic cultures, including Daxi, Qujialing, Shijiahe, Majiabang, Songze, Liangzhu, and Beiyinyangying in the middle and lower Yangtze, and several shell midden sites in Lingnan, were also discovered in this phase.

During the systematic research phase (1970s to the present), ongoing major excavation at many sites contributed significantly to our understanding of prehistoric southern China. Additional early human remains at Wushan, Jianshi, Yunxian, Nanjing, and Hexian were recovered together with Palaeolithic assemblages from Yuanmou, the Baise basin, Jianshi Longgu cave, Hanzhong, the Li and Yuan valleys, Dadong and Jigongshan. Early rice remains were discovered in the Neolithic sites of Pengtoushan, Xianrendong, and Yuchanyan, creating a broader picture of the origin, development, and dispersal of early agriculture in southern China. In the Lingnan-Fujian region and the Yungui Plateau, new cultural

Zhang Chi is Professor in the Department of Archaeology, Peking University, in Beijing, China. Hsiao-chun Hung recently received her Ph.D from the Department of Archaeology and Natural History, Australian National University, Canberra. 


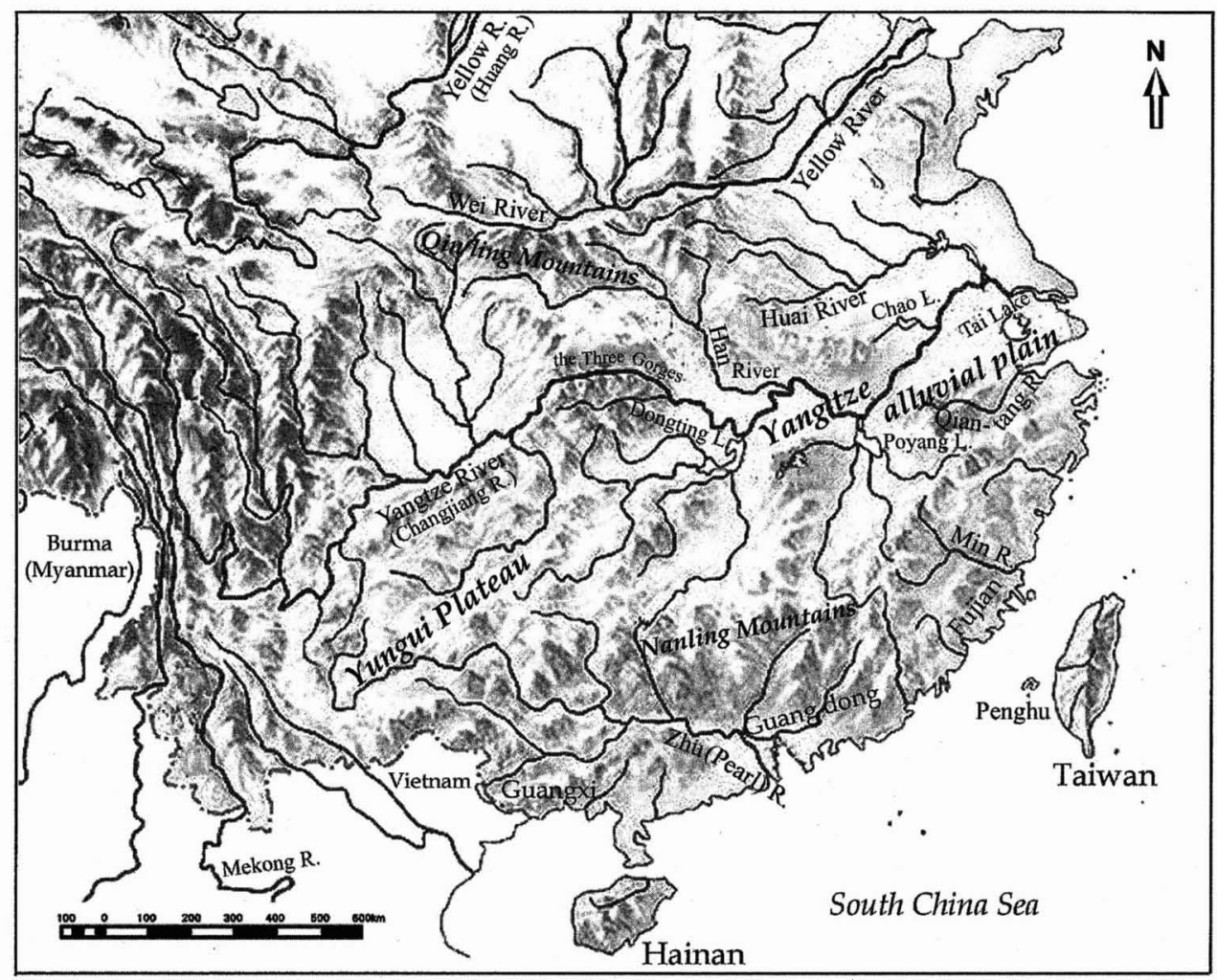

Fig. 1. The geographic regions and landforms of China. In this paper, southern China refers to the geographic region between the Qinling Mountains and the Huai River Valley and the Chinese national boundary with countries in Mainland Southeast Asia.

discoveries included Tanshishan in Fujian, Shixia in Guangdong, and Baoduncun in Sichuan. Many other sites have also been discovered in Guangxi, Yunnan, and Chongqing. These new discoveries illuminate aspects of prehistoric societies in the region such as farming (e.g., Yan 1997), settlement patterns (e.g., C. Zhang 2003), social structure (e.g. Meng 1997), and pottery, lithics, and jade working (e.g., C. Zhang 2000c). Our knowledge of cultural chronology in southern China has also developed immensely.

\section{THE TRANSITION FROM LATE PALAEOLITHIC TO EARLY NEOLITHIC}

During the late Palaeolithic, following the last glacial maximum, the Palaeolithic pebble tool industries of southern China became influenced by the northern China tradition of small flake tool production, characterized especially by scrapers and pointed tools (Y. Wang 2003, 2005). Some related studies also propose that there was a shift to more animal hunting at this time, with less emphasis on plant gathering than previously (Y. Wang 2005).

The period between 16,000 and 10,000 years ago was of uncertain significance 


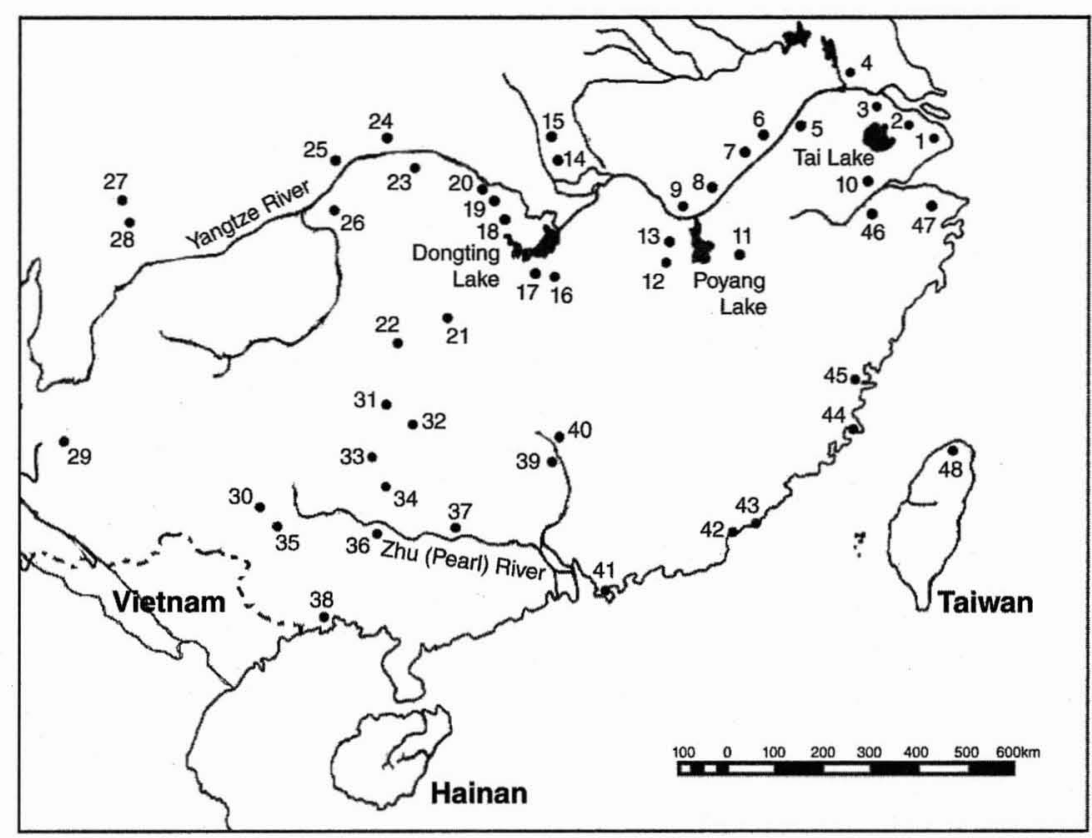

Fig. 2. The major Neolithic sites of southern China mentioned in this paper. 1: Guangfulin/ Maqiao/Songze; 2: Caoxieshan; 3: Majiabang; 4: Nandang; 5: Beiyinyangying/Zanmiao; 6: Lingjiatan; 7: Zhangsidun; 8: Xuejiagang; 9: Ludun; 10: Liangzhu; 11: Xianrendong/Diaotonghuan; 12: Shinianshan/Fanchengdui; 13: Shanbei; 14: Shijiahe; 15: Qujialing; 16: Daiziping; 17: Datang; 18 : Tangjiagang; 19: Bashidang/Chengtoushan/Pengtoushan; 20: Zaoshi; 21: Doupengpo; 22: Gaomiao; 23: Chengbeixi/Honghuatao/Yangjiawan; 24: Guandukou; 25: Daxi; 26: Yuxi/Yuxiping; 27: Yingpanshan; 28: Baoduncun; 29: Dian Lake; 30: Gexinqiao; 31: Xiaojin; 32: Yuchanyan; 33: Dayan/ Miaoyan/Zengpiyan; 34: Liyuzui; 35: Beidaling; 36: Dingsishan; 37: Wusaoling; 38: Fangcheng; 39: Shilaodun; 40: Shixia; 41: Xiantouling; 42: Shiweishan; 43: Chenqiaocun; 44: Keqiutou; 45: Tanshishan; 47: Hemudu; 46: Kuahuqiao; 48: Dabenkeng.

in the rise of farming in China (C. Zhang 2000a:190-198). During that period, referred to as early Neolithic by Chinese archaeologists, owing to the presence of pottery, most habitation sites appear to have been located in limestone caves in the foothills of the Nanling mountain range. Subsistence evidence comes mainly in the form of large numbers of riverine gastropods ( $N$. He 1988:158-166), seeds, and even a few rice remains (see below). Excavations in the caves of Xianrendong in Wannian (Zhang and Liu 1996); Yuchanyan in Daoxian (J.-R. Yuan 1996); and Miaoyan (S. Chen 1999), Zengpiyan (Institute of Archaeology, CASS et al. 2003) and Dayan (Fu et al. 2001) in Guilin, have produced the earliest pottery in China (C. Zhang 2000a, 2000b, 2006; see Fig. 2 and Table 1). Most vessels are either round-based jars with linear incision or cord impressed surfaces, or deep bowls, sometimes with weaving impressions. Coarse quartz grit was used as a tempering agent. The lithic industry at this time was still characterized by pebble tools that included unifacial choppers, flaked hoes and axes, perforated pebbles, and a few cutting tools with polished edges. Small flake tools of chert and quartz are also present in some cave middens. Bone awls, needles, arrowheads, fishing 
Table I. Radiocarbon Dates from Early Neolithic Sites in Southern China (ALL DATED MATERIALS WERE ASSOCIATED WITH POTTERY)

\begin{tabular}{|c|c|c|c|c|}
\hline LOCATION, SITE & LAB NO. & DATE, B.P. & METHOD, MATERIAL & REFERENCES CITED \\
\hline \multirow[t]{5}{*}{ Xianrendong } & BA95136 & $19780 \pm 360$ & AMS, Charcoal & C. Zhang $2000 b: 47$ \\
\hline & UCR3555 & $15050 \pm 60$ & AMS, Charcoal & C. Zhang $2000 b: 47$ \\
\hline & UCR3561 & $12430 \pm 80$ & AMS, Charcoal & C. Zhang $2000 b: 47$ \\
\hline & ZK-39 & $10870 \pm 240$ & ${ }^{14} \mathrm{C}$, Shell & $\begin{array}{l}\text { Institute of Archaeology, } \\
\text { CASS } 1974: 337\end{array}$ \\
\hline & ZK-92-0 & $8575 \pm 235$ & ${ }^{14} \mathrm{C}$, Animal bone & $\begin{array}{l}\text { Jiangxi Provincial Museum } \\
\text { 1976:35 }\end{array}$ \\
\hline \multirow[t]{6}{*}{ Yuchanyan } & BA95057b & $14810 \pm 230$ & $\begin{array}{l}\text { AMS, Food residue } \\
\text { on sherd }\end{array}$ & $\begin{array}{l}\text { S. Yuan et al. 1997:392, } \\
\text { 803-806 }\end{array}$ \\
\hline & BA95057a & $12320 \pm 120$ & AMS, Humic acid & S. Yuan et al. 1997:803-806 \\
\hline & $?$ & $14490 \pm 230$ & AMS, Charcoal & S. Yuan et al. 1997:803-806 \\
\hline & ZK-2903 & $8194 \pm 610$ & ${ }^{14} \mathrm{C}$, Animal bone & $\begin{array}{l}\text { Institute of Archaeology, } \\
\text { CASS 1997:38 }\end{array}$ \\
\hline & ZK-2902 & $8820 \pm 399$ & ${ }^{14} \mathrm{C}$, Animal bone & $\begin{array}{l}\text { Institute of Archaeology, } \\
\text { CASS 1997:38 }\end{array}$ \\
\hline & ZK-2901 & $7707 \pm 413$ & ${ }^{14} \mathrm{C}$, Animal bone & $\begin{array}{l}\text { Institute of Archaeology, } \\
\text { CASS 1997:38 }\end{array}$ \\
\hline \multirow[t]{7}{*}{ Miaoyan } & $2 \mathrm{~K}-2841$ & $17238 \pm 237$ & ${ }^{14} \mathrm{C}$, Shell & S. Chen 1999: 163 \\
\hline & BA92036-1 & $18140 \pm 320$ & ${ }^{14} \mathrm{C}$, Animal bone & S. Chen 1999: 163 \\
\hline & BA94137b & $15660 \pm 260$ & $\begin{array}{l}\text { AMS, Food residue } \\
\text { on sherd }\end{array}$ & S. Yuan et al. 1997:803-806 \\
\hline & BA94137a & $15560 \pm 500$ & AMS, Humic acid & S. Yuan et al. 1997:803-806 \\
\hline & BA92036-1 & $18140 \pm 320$ & ${ }^{14} \mathrm{C}$, Shell & S. Chen $1999: 163$ \\
\hline & BA92034-1 & $13710 \pm 270$ & ${ }^{14} \mathrm{C}$, Shell & S. Chen 1999:163 \\
\hline & ZK-2841 & $17238 \pm 237$ & ${ }^{14} \mathrm{C}$, Shell & S. Chen $1999: 163$ \\
\hline \multirow[t]{13}{*}{ Zengpiyan } & ZK-0279-1 & $11310 \pm 180$ & ${ }^{14} \mathrm{C}$, Shell & $\begin{array}{l}\text { Institute of Archaeology, } \\
\text { CASS 1977:203 }\end{array}$ \\
\hline & ZK-280-0 & $7580 \pm 410$ & ${ }^{14} \mathrm{C}$, Animal Bone & $\begin{array}{l}\text { Institute of Archaeology, } \\
\text { CASS 1978:283 }\end{array}$ \\
\hline & SB36c-SB35c & $\begin{array}{c}10370 \pm 870- \\
9240 \pm 620\end{array}$ & TL, sherds & W. Wang 1984:324 \\
\hline & ZK316805 & $11596 \pm 91$ & ${ }^{14} \mathrm{C}$, Shell & $\begin{array}{l}\text { Institute of Archaeology, } \\
\text { CASS et al. 2003:437 }\end{array}$ \\
\hline & ZK316803 & $11000 \pm 112$ & ${ }^{14} \mathrm{C}$, Shell & $\begin{array}{c}\text { Institute of Archaeology, } \\
\text { CASS et al. 2003:437 }\end{array}$ \\
\hline & ZK316803b & $11235 \pm 141$ & ${ }^{14} \mathrm{C}$, Shell & $\begin{array}{l}\text { Institute of Archaeology, } \\
\text { CASS et al. 2003: } 437\end{array}$ \\
\hline & ZK316806 & $11575 \pm 112$ & ${ }^{14} \mathrm{C}$, Shell & $\begin{array}{l}\text { Institute of Archaeology, } \\
\text { CASS et al. } 2003: 437\end{array}$ \\
\hline & ZK316806b & $11438 \pm 85$ & ${ }^{14} \mathrm{C}$, Shell & $\begin{array}{l}\text { Institute of Archaeology, } \\
\text { CASS et al. } 2003: 437\end{array}$ \\
\hline & ZK316811 & $10996 \pm 68$ & ${ }^{14} \mathrm{C}$, Shell & $\begin{array}{l}\text { Institute of Archaeology, } \\
\text { CASS et al. 2003:437 }\end{array}$ \\
\hline & ZK316813 & $10944 \pm 132$ & ${ }^{14} \mathrm{C}$, Shell & $\begin{array}{l}\text { Institute of Archaeology, } \\
\text { CASS et al. 2003:437 }\end{array}$ \\
\hline & BA01245 & $10500 \pm 140$ & AMS, Charcoal & $\begin{array}{l}\text { Institute of Archaeology, } \\
\text { CASS et al. 2003:441 }\end{array}$ \\
\hline & BA01246 & $11960 \pm 240$ & AMS, Charcoal & $\begin{array}{l}\text { Institute of Archaeology, } \\
\text { CASS et al. 2003:441 }\end{array}$ \\
\hline & BA01239 & $9440 \pm 280$ & AMS, Charcoal & $\begin{array}{l}\text { Institute of Archaeology, } \\
\text { CASS et al. 2003:441 }\end{array}$ \\
\hline
\end{tabular}


TABLE I (Continued)

\begin{tabular}{|c|c|c|c|c|}
\hline LOCATION, SITE & LAB NO. & DATE, B.P. & METHOD, MATERIAL & REFERENCES CITED \\
\hline & BA01244 & $9380 \pm 170$ & AMS, Charcoal & $\begin{array}{r}\text { Institute of Archaeology, } \\
\text { CASS et al. 2003:441 }\end{array}$ \\
\hline & BA01243 & $9770 \pm 130$ & AMS, Charcoal & $\begin{array}{l}\text { Institute of Archaeology, } \\
\text { CASS et al. 2003:441 }\end{array}$ \\
\hline & BA01238 & $9380 \pm 180$ & AMS, Charcoal & $\begin{array}{l}\text { Institute of Archaeology, } \\
\text { CASS et al. 2003:441 }\end{array}$ \\
\hline & BA01242 & $9490 \pm 190$ & AMS, Charcoal & $\begin{array}{l}\text { Institute of Archaeology, } \\
\text { CASS et al. 2003:441 }\end{array}$ \\
\hline & ANU-11734 & $9350 \pm 250$ & AMS, Charcoal & $\begin{array}{l}\text { Institute of Archaeology, } \\
\text { CASS et al. 2003:443 }\end{array}$ \\
\hline & ANU-11733 & $10520 \pm 280$ & AMS, Charcoal & $\begin{array}{l}\text { Institute of Archaeology, } \\
\text { CASS et al. 2003:443 }\end{array}$ \\
\hline & ANU-11728 & $9130 \pm 160$ & AMS, Charcoal & $\begin{array}{l}\text { Institute of Archaeology, } \\
\text { CASS et al. 2003:443 }\end{array}$ \\
\hline
\end{tabular}

Methods: AMS - accelerator mass spectrometry carbon-14 dating; ${ }^{14} \mathrm{C}$ - conventional radiocarbon dating; TL-thermal-luminescence dating. CASS: Chinese Academy of Social Sciences.

spear points, and shell knives with one or two holes are also widespread. Associated calibrated ${ }^{14} \mathrm{C}$ dates (excluding those on freshwater shell) from these sites fall between 16,000 and 10,000 years ago (Table 1).

Hunted animals included deer, pigs, birds, fish, freshwater turtles, and shellfish, indicating that hunting and gathering were still major food procurement strategies during this phase (Institute of Archaeology, CASS et al. 2003:341-346). Remains of several edible plants, such as Chinese gooseberries (Actinidia chinendia and Actinidia sp.), wild grapes (Vitis sp.), plums (Prunus mume), and Chinese hackberries (Celtis tetrandra) were discovered during flotation in Yuchanyan and Zengpiyan caves (Institute of Archaeology, CASS et al. 2003:286-294; J.-R. Yuan 2000:35). Three grains of rice unearthed from Yuchanyan in 1993 and 1995 have been identified both as morphologically wild by Crawford and Chen (1998), and as early cultivated rice (O. sativa L., subsp. ancient zhang) by Zhang (W. Zhang 2000:122). Phytoliths of similar age found in Xianrendong and Diaotonghuan caves have been identified as morphologically wild (Z. Zhao 1998). Because of problems with the small sample sizes in these cave sites, Nakamura (2000:1-11) believes that reliable evidence for rice cultivation in this phase is uncertain. It should also be noted that none of these early rice grains have been directly AMS dated. Fuller et al. (2007) commence wild rice food production during the basal phase at Hemudu (c. 5000 B.c.), or perhaps a millennium earlier, which is much later than the late Pleistocene phases discussed above.

Although these limestone cave habitation sites continue a Palaeolithic cave occupation tradition, the occurrences of pottery and possibly wild rice remains suggest a changing economic strategy. This phase thus overlaps with the following middle Neolithic phase of Chinese archaeologists in southern China. Its duration would appear to have been quite long, and future research on the transformation to the Neolithic is badly needed, especially on the palaeobotany of the period. 


\section{MIDDLE AND LATE NEOLITHIC CULTURES OF THE MIDDLE AND LOWER YANGTZE RIVER BASIN}

The development and dispersal of farming in southern China was a long process. In this article we divide the agricultural Neolithic of the middle and lower Yangtze basin into four phases: middle Neolithic (8000-5000 B.C.), early phase of the late Neolithic (5000-3500 B.c.), late phase of the late Neolithic (35002500 в.с.), and terminal Neolithic (2500-2000 в.с.) (С. Zhang 2003; Table 2).

\section{The Middle Neolithic ( $8000-5000$ B.C.)}

The first phase of pre-domestication cultivation in the middle and lower Yangtze basin occurred at this time. Although the number of discovered sites is not large, the overall cultural sequence is well established. The key sites belong to the Pengtoushan-Zaoshi Culture of the Li River basin (Dongting Lake region), the Datang culture of the middle and lower Xiang basin, and the ShangshanKuahuqiao culture of the Qiantang basin (lower Yangtze) (Figs 2 and 3:I). Most sites are now located outside caves, on riverine terraces that could have supported cultivation.

As an example of a settlement of this phase, Bashidang in Lixian County, Hunan, covered more than 30,000 sq. m, or 3 ha (Institute of Archaeology, Hunan Province 1996:26-39, 2006:213-275; Pei 1998:1). It was enclosed by a ditch and low earthen bank, and within the 1000 excavated square meters, 24 earthen floors, 98 graves, 80 pits, and a group of raised-floor constructions were discovered. Most earthen floors covered about 30 to 40 sq. $\mathrm{m}$ and were located on higher land in the north and northwest of the site, together with the raisedfloor constructions. Inhumation burials were scattered between the houses. Most contained a few pots or stone tools as grave goods, but there were no signs of major differences in wealth or social differentiation.

In terms of economic developments, considerable quantities of rice husks were incorporated into pottery at Shangshan, dated c. 8000 B.C., and these have been identified as cultivated rice by Jiang and Liu (2006). However, Fuller et al. (2007) note that fully domesticated non-shattering forms were not yet present, indicating wild plant food procurement or production. At Kuahuqiao, several thousand husks and grains of ancient cultivated rice (Institute of Archaeology, Zhejiang Province and Xiaoshan Museum 2004:273-277) and evidence of animal domestication, especially of dogs and pigs (Institute of Archaeology, Zhejiang Province and Xiaoshan Museum 2004:249-254), were also recovered. Heavily exploited wild nut and fruit-bearing plants include Prunus persica, Prunus mume, Prunus armeniaca, Quercus acutissima, Quercus variabilis, Quercus fabri, Choerospondias axillaries, Trapa bicornis, Trapa quadrispinosa, and Euryale ferox. Seeds of Leguminosae, Cucurbitaceae, Theaceae, and Polygonaceae were also unearthed (Institute of Archaeology, Zhejiang Province and Xiaoshan Museum 2004:271). In the middle Yangtze basin, 20,000 rice husks and grains were collected during a small-scale excavation at Bashidang. These have been identified as ancient cultivated rice, but not identical to any of the present-day indica or japonica varieties (Zhang and Pei 1997:36-41).

Many rice remains have also been reported from Pengtoushan. Some doubt whether this was domesticated rice (Crawford and Chen 1998), yet it is evident 
Table 2. Chronologies of Yangtze Basin Neolithic Cultures (see Figs. 2 and 3)

\begin{tabular}{|c|c|c|c|c|c|c|c|}
\hline \multirow[b]{2}{*}{ AGE } & \multirow[b]{2}{*}{ PHASE } & \multirow{2}{*}{$\begin{array}{l}\text { UPPER YANGTZE } \\
\text { XIA-JIANG REGION }\end{array}$} & \multicolumn{5}{|c|}{ MID- TO LOWER YANGTZE } \\
\hline & & & $\begin{array}{c}\text { MID-HAN RIVER } \\
\text { REGION } \\
\text { NANYANG BASIN } \\
\text { XIANGFAN VALLEY } \\
\text { SUIZAO CORRIDOR }\end{array}$ & $\begin{array}{c}\text { TWO LAKES } \\
\text { REGION } \\
\text { JIANGHAN PLAIN } \\
\text { DONGTING LAKE } \\
\text { PLAIN }\end{array}$ & $\begin{array}{c}\text { GAN-BO REGION } \\
\text { GAN VALLEY } \\
\text { POYANG LAKE PLAIN }\end{array}$ & $\begin{array}{l}\text { SU-WAN REGION } \\
\text { SU-WAN PLAIN } \\
\text { CHAO LAKE PLAIN } \\
\text { NINGZHEN AREA }\end{array}$ & $\begin{array}{l}\text { JIANG-ZHE REGION } \\
\text { YANGTZE DELTA }\end{array}$ \\
\hline $\begin{array}{l}10,000-8000 \\
\text { B.C. }\end{array}$ & Early Neolithic & & & $\begin{array}{l}\text { Yuchanyan Cave } \\
\text { site }\end{array}$ & $\begin{array}{l}\text { Xianrendong Cave } \\
\text { and Diaotonghuan } \\
\text { Cave sites }\end{array}$ & & \\
\hline $\begin{array}{l}8000-5000 \\
\text { в.C. }\end{array}$ & Middle Neolithic & $\begin{array}{l}\text { Chengbeixi culture } \\
\text { Lower Yuxi culture }\end{array}$ & Peiligang culture* & $\begin{array}{l}\text { Pengtoushan- } \\
\text { Zaoshi culture } \\
\text { Datang culture }\end{array}$ & & & $\begin{array}{l}\text { Shangshan- } \\
\text { Kuahuqiao } \\
\text { culture }\end{array}$ \\
\hline $\begin{array}{l}5000-3500 \\
\text { B.C. }\end{array}$ & $\begin{array}{l}\text { Early phase of } \\
\text { late Neolithic }\end{array}$ & $\begin{array}{l}\text { Early Daxi culture } \\
\text { Middle Daxi } \\
\text { culture } \\
\text { Late Daxi culture }\end{array}$ & $\begin{array}{l}\text { Early Yangshao } \\
\text { culture* } \\
\text { Mid Yangshao } \\
\text { culture* } \\
\text { Late Yangshao } \\
\text { culture* }\end{array}$ & $\begin{array}{l}\text { Early Daxi culture } \\
\text { Middle Daxi } \\
\text { culture } \\
\text { Late Daxi culture }\end{array}$ & $\begin{array}{l}\text { Phase I, Shinianshan } \\
\text { culture } \\
\text { Phase II, Shinianshan } \\
\text { culture }\end{array}$ & $\begin{array}{l}\text { Beiyinyangyin } \\
\text { culture } \\
\text { Xuejiagang culture }\end{array}$ & $\begin{array}{l}\text { Hemudu culture } \\
\text { Majiabang culture } \\
\text { Early Songze } \\
\quad \text { culture } \\
\text { Late Songze culture }\end{array}$ \\
\hline $\begin{array}{l}3500-2500 \\
\text { B.C. }\end{array}$ & $\begin{array}{l}\text { Late phase of } \\
\text { late Neolithic }\end{array}$ & $\begin{array}{l}\text { Qujialing culture } \\
\text { Early Shijiahe } \\
\text { culture } \\
\text { Middle Shijiahe } \\
\text { culture }\end{array}$ & $\begin{array}{l}\text { Qujialing culture } \\
\text { Early Shijiahe } \\
\text { culture } \\
\text { Middle Shijiahe } \\
\text { culture }\end{array}$ & $\begin{array}{l}\text { Qujialing culture } \\
\text { Early Shijiahe } \\
\text { culture } \\
\text { Middle Shijiahe } \\
\text { culture }\end{array}$ & $\begin{array}{l}\text { Early Fanchengdui } \\
\text { culture } \\
\text { Late Fanchengdui } \\
\text { culture } \\
\text { Shanbei culture }\end{array}$ & $\begin{array}{l}\text { Ludun remains } \\
\text { Zanmiao remains } \\
\text { Early Zhangsidun } \\
\quad \text { remains }\end{array}$ & $\begin{array}{l}\text { Early Liangzhu } \\
\text { culture } \\
\text { Middle Liangzhu } \\
\text { culture } \\
\text { Late Liangzhu } \\
\text { culture }\end{array}$ \\
\hline $\begin{array}{l}2500-2000 \\
\text { B.C. }\end{array}$ & $\begin{array}{l}\text { Terminal } \\
\text { Neolithic }\end{array}$ & $\begin{array}{l}\text { Late Shijiahe } \\
\text { culture }\end{array}$ & $\begin{array}{l}\text { Late Shijiahe } \\
\text { culture }\end{array}$ & $\begin{array}{l}\text { Late Shijiahe } \\
\text { culture }\end{array}$ & & $\begin{array}{l}\text { Late Zhangsidun } \\
\text { remains }\end{array}$ & Nandang culture \\
\hline
\end{tabular}

* Northern China Neolithic tradition. 
Middle Neolithic, 8000 5000 BC

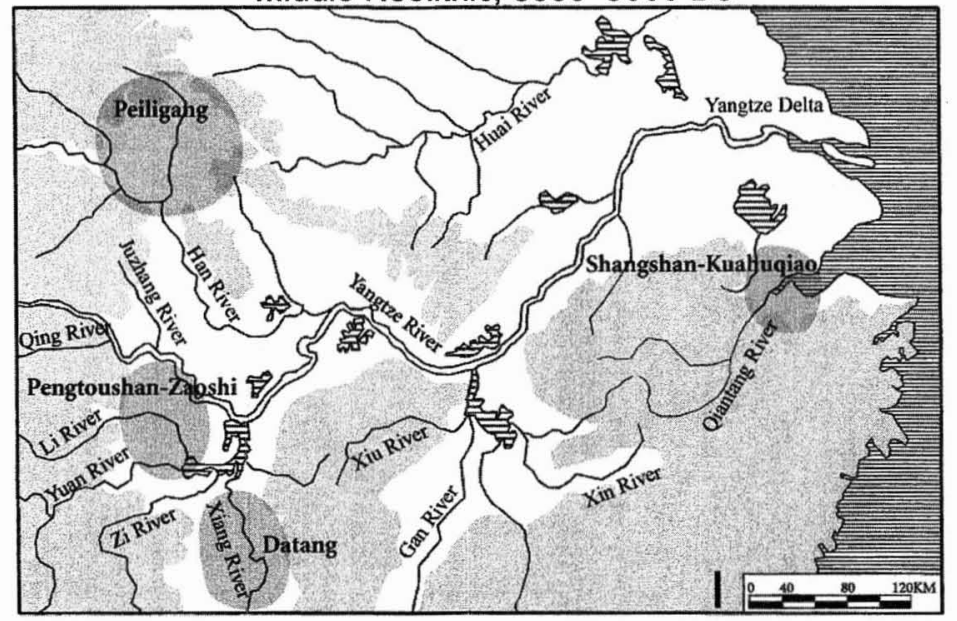

Late Phase of Late Neolithic, 3500 2500 BC

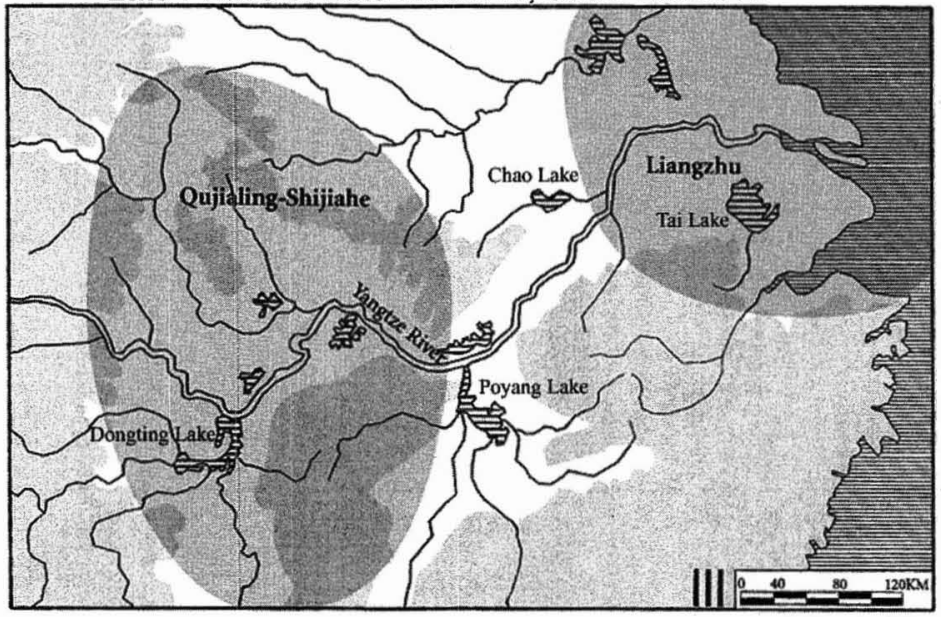

Early Phase of Late Neolithic, 5000 3500 BC

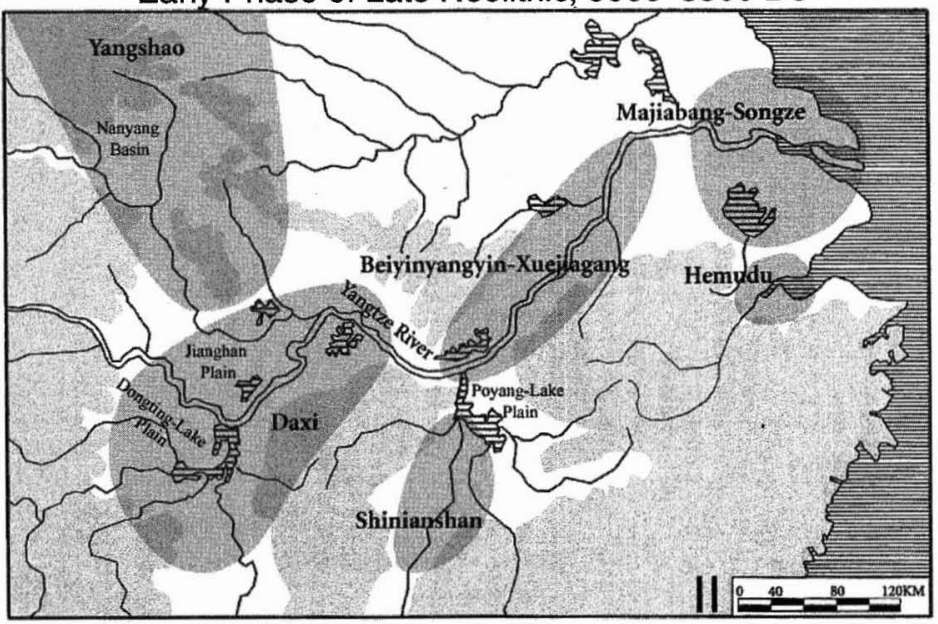

Terminal Neolithic, 2500 2000 BC

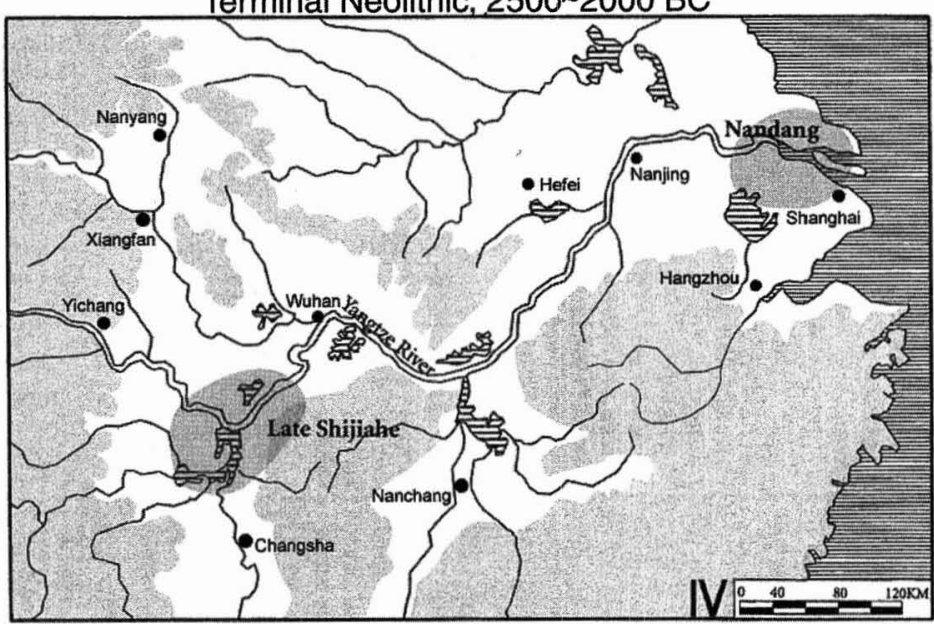

Fig. 3. The distribution of Neolithic cultures in the middle and lower Yangtze Valley. (Shaded area: 500-m elevation; solid circles: modern cities.) 
from the quantity found in the site that food production was already beginning at this time. There is ambiguous evidence for domesticated pigs and chickens in sites of the Pengtoushan-Zaoshi culture (Pei 2000). In the later middle Neolithic, a spinning and weaving industry arose in the Kuahuqiao and Zaoshi cultures. Kuahuqiao alone has produced over 100 baked clay spindle whorls. Remarkably, a $\log$ boat made of pine was recently discovered at Kuahuqiao, $560 \mathrm{~cm}$ long and $52 \mathrm{~cm}$ in beam (Institute of Archaeology, Zhejiang Province and Xiaoshan $\mathrm{Mu}-$ seum $2004: 375)$.

By middle Neolithic times, therefore, the food producing subsistence system of Neolithic southern China was in formation. Rice was under cultivation in predomesticated form, incipient domestication of pigs and chickens was under way, but various aquatic and non-cultivated forest plants, such as water caltrop, lotus, and oak (acorns), together with wild animals, were still probably of major importance in the diet.

\section{The Early Phase of the Late Neolithic (5000-3500 в.с.)}

This phase is characterized by a major increase in site numbers, indicating rapid population growth in the middle and lower Yangtze basin. Relevant cultures include Daxi ${ }^{4}$ in the Two Lakes region ${ }^{5}$ (Jianghan plain and Dongting Lake plain), Yangshao in the Han Valley, Beiyinyangying and Xuejiagang on the plains of the $\mathrm{Su}-\mathrm{W}$ an region, ${ }^{6}$ Shinianshan in the Gan-Po region, ${ }^{7}$ and Hemudu, Majiabang and Songze in the Jiang-Zhe region ${ }^{8}$ (Jiangsu and Zhejiang Provinces; Figs. 2 and $3:$ II).

In the early phase of the late Neolithic, the first evidence appears for increasing hierarchy in settlement size and increasing complexity of social organization. Settlements now average 2-3 ha in size, such as Tangjiagang in Hunan (Hunan Provincial Museum 1982; Pei 1992), with presumably more than 100 residents in each village. Xiawanggang (Institute of Archaeology, Henan Province 1989:166183) and Baligang (Archaeological Team of the Peking University 1989:31-45) in the middle Han Valley are both 1000-2000 sq. $\mathrm{m}$ in size, and each has two rows of houses. One house row at Xiawanggang has been excavated, and consists of 29 rooms joined in a single terrace (Fig. 4). Allowing an average of 4 persons to a household, each row might have held 100 people, giving a total of 200 for the whole settlement. Burials occur in clusters that can hold more than 100 or even 1000 graves (such as at Sanxingcun in Jiangsu, National Bureau of Cultural Relics 2000:11-19), potentially for separate lineage/clan groups. The quantities of grave goods now begin to vary between burials and between clusters. For example, in some clusters the average grave has only a few mortuary objects, but in others there is more wealth (C. Zhang 2003).

The largest settlements are between 10 and 20 ha in size; Lingjiatan in Hanshan, the most extensive settlement of this phase ever excavated, covers more than 1 sq. km (Institute of Archaeology, Anhui Province 1989, 1999, 2006; J. Zhang 1991). These large settlements reveal evidence for craft specialization, for example the pottery workshop at Chengtoushan (Institute of Archaeology, Hunan Province 1999, 2007) and the jade workshop at Lingjiatan. At Chengtoushan, eight pottery kilns were excavated, with working areas and clay collecting areas nearby. Very few kilns have been found in contemporary smaller 

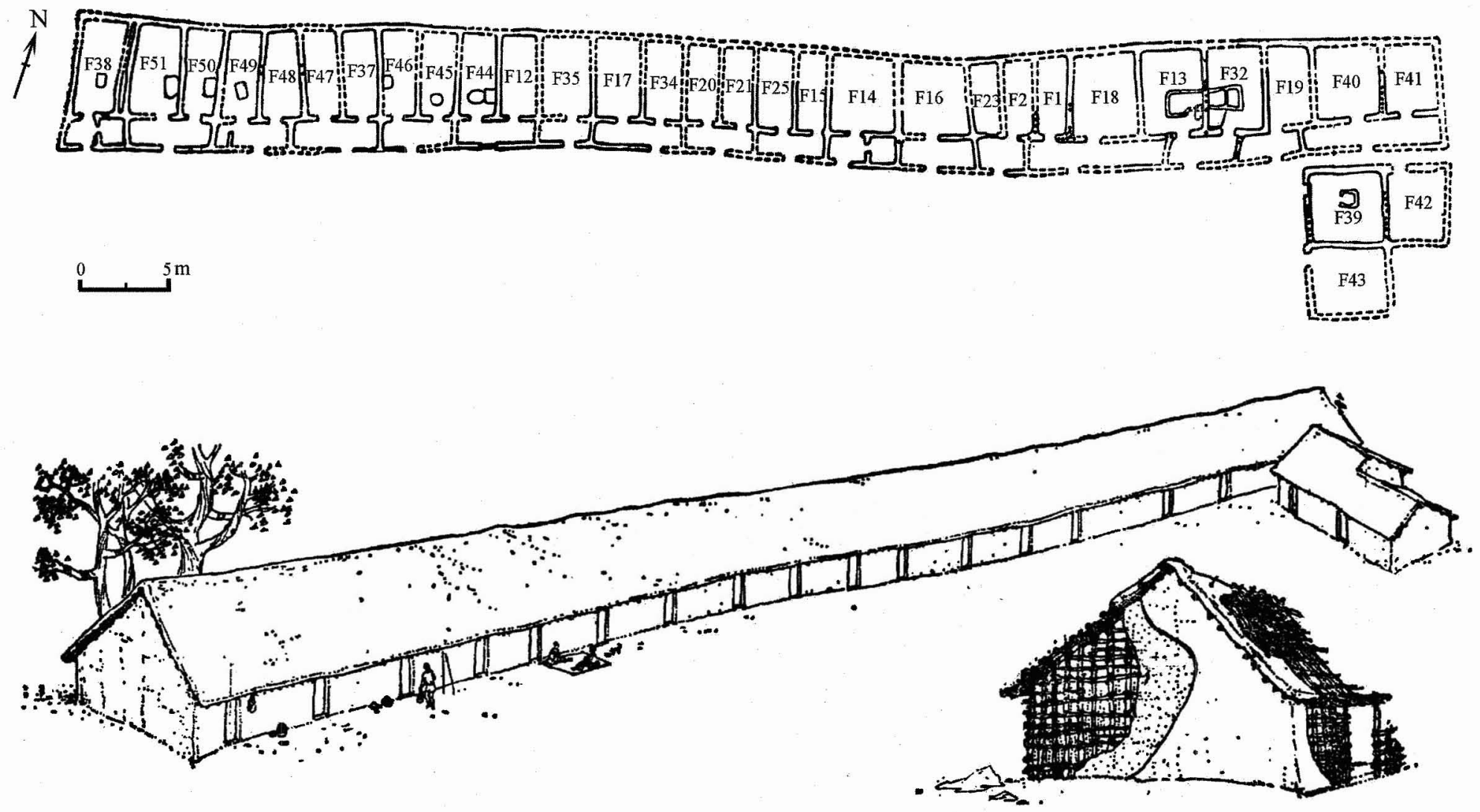

Fig. 4. Plan and reconstruction of a longhouse at Xiawanggang, Xichuan, Henan (from Institute of Archaeology, Henan Province 1989:165). 
settlements, suggesting that Chengtoushan may have been a specialized pottery producing site.

Lingjiatan was a very important jade workshop during this phase. In the northern cemetery in this site, many burials contained more than 100 exquisite jade and stone artifacts as mortuary objects, sometimes together with large numbers of manufacturing tools for jade production, and discarded jade fragments. Such rich discoveries are so far absent in the cemeteries of smaller settlements. Chengtoushan also has evidence for ceremonial platform construction, suggesting that the large settlements probably served as regional ceremonial centers.

Remains of rice fields have been unearthed in some lower Yangtze MajiabangSongze sites, such as Caoxieshan (H. Zou et al. 2000:97-113). On average, these very small fields enclose 3 to 5 sq. $\mathrm{m}$ and are surrounded by low earthen banks. Large numbers of spades made of bone or wood come from the contemporaneous Hemudu site, but there is no evidence for plow cultivation until the late Songze (see below). In the early phase of the middle Yangtze Daxi culture, a phase often referred to as Tangjiagang (Hunan Provincial Museum 1982; Pei 1992), rice fields were much larger and enclosed more than 2000 sq. m, indicating that the scale of field agriculture in the alluvial plain of the Two Lakes region was larger than in the lower Yangtze basin. Between 15 and 26 percent of consumed meat from settlements of this phase belong to domesticated pigs (J. Yuan 1999:8). Because of the local absence of raw materials for manufacturing stone tools, farmers living on the alluvial plains obtained stone artifacts by exchange. Lithic and jade artifacts that originated in the $\mathrm{Su}-\mathrm{W}$ an region became very widespread (C. Zhang 2003:123-134).

\section{The Late Phase of the Late Neolithic (3500-2500 B.C.)}

During this late phase of the late Neolithic, c. 3500-2500 B.C., social structures and settlement patterns in the middle and lower Yangtze basin changed dramatically in the direction of greater hierarchy and complexity. Two nuclear areas developed, focused on the Qujialing-Shijiahe culture located in the Two Lakes region and the Liangzhu culture located in the Tai Lake region. Current evidence suggests that the adjacent regional cultures located in the middle Han Valley ${ }^{9}$ and in the Su-Wan, Gan-Po, and northern Jiangsu regions did not undergo such developments toward complexity (Figs. 2 and $3:$ III).

The Two Lakes and Tai Lake regions had dense populations in this phase. In the Two Lakes region, the Shijiahe site complex covers a total area of over $8 \mathrm{sq}$. $\mathrm{km}$. A one-sq.-km urban complex is located in the center, surrounded by a $60-$ 80-m-wide trench. Many smaller settlements encircle this central area (Department of Archaeology, Peking University et al. 1992:213-294). In the Tai Lake region, the Liangzhu complex includes over 130 settlements distributed through 40 sq. km (Institute of Archaeology, Zhejiang Province 2005a:314-326). Interestingly, unoccupied zones occur between these big site complexes, suggesting that the domain of each cluster was almost as large as a modern Chinese county. Such large Neolithic settlement complexes never occurred in previous phases, and the uninhabited zones between them could suggest very tense social relations.

There is strong evidence from settlement hierarchies to suggest rank differentiation by this time. Large complexes such as Liangzhu contain specialized work- 
shops for production of jade ornaments. The smaller site clusters ( 1 to 2 ha) have not yet produced such evidence. There is also evidence for burial hierarchy. Most Liangzhu graves have very few mortuary objects, but rich graves placed in high artificial mounds usually have several hundred jade ornaments and items of lacquered woodwork (Fig. 5). The most famous cemeteries of the Liangzhu phase, Yaoshan (Institute of Archaeology, Zhejiang Province 2003) and Fanshan (Institute of Archaeology, Zhejiang Province 2005b), are both located in high platforms built of multicolored layers of soil and stone.

Plow cultivation first appeared in the late Songze phase, and became very well developed in the Liangzhu phase (e.g., Mou and Song 1981:75-84; You 1996:143-150). In Liangzhu, the evidence for plow cultivation comes from several new types of agricultural implement, such as the so-called winged implements believed to be plows by many Chinese archaeologists, and large triangular stone blades. There are also rectangular and semilunar knives with holes, and stone sickles. Domesticated pigs by this time contributed about 70 percent of the consumed meat (J. Yuan 1999:8). During the Songze phase, production of domesticated crops became the major subsistence strategy, as emphasized by Fuller et al. (2007). The Two Lakes and Tai Lake regions had excellent environmental conditions for wet-field rice agriculture, as also noted by Ruddiman (2005; Ruddiman et al. in press), in his argument for increased methane and carbon dioxide levels in the atmosphere as a result of increasing wet rice production in Asia from this time onward. The Two Lakes and Tai Lake regions also became nuclear regions, in terms of settlement and population density, into which craft specialists migrated from outlying regions. For instance, the center of jade production moved from the Su-Wan region to the Tai Lake region (C. Zhang $2003: 220)$.

\section{The Terminal Neolithic (2500-2000 B.C.)}

In this phase, the Neolithic cultures in the middle and lower Yangtze basin evidently declined. The large Qujialing-Shijiahe and Liangzhu settlements appear to have been abandoned in favor of small settlements mostly located in the northern Yangtze Valley. These include the late Shijiahe and post Shijiahe sites of the Two Lakes region (Department of Archaeology, Peking University et al. 1992; Meng 1997), and the Nandang or Guangfulin culture of the lower Yangtze basin (Institute of Archaeology, Nanjing Museum et al. 1995, 1997; Longqiuzhuang Archaeological Team 1999; Figs. 2 and 3:IV).

The cause of the decline of the Neolithic cultures in this region is still uncertain, but one of the reasons could be related to the expansion of late Longshan cultures from the Yellow River Valley (C. Zhang 1997:65). The late Dawenkou culture of the Yellow River Valley expanded as far south as the northern bank of the Yangtze (Nanjing Museum 1993:87-88). ${ }^{10}$ The late Shijiahe culture maintained close relations with the late phase of the Dawenkou culture, so that some scholars consider that the late Shijiahe was not directly derived from the early Shijiahe at all (C. Zhang 1997:65). During the terminal Neolithic, the lower Yangtze became the borderland for the Wangyoufang facies of the northern Longshan culture.

In this phase, site numbers in the Yangtze River basin are relatively few-only 


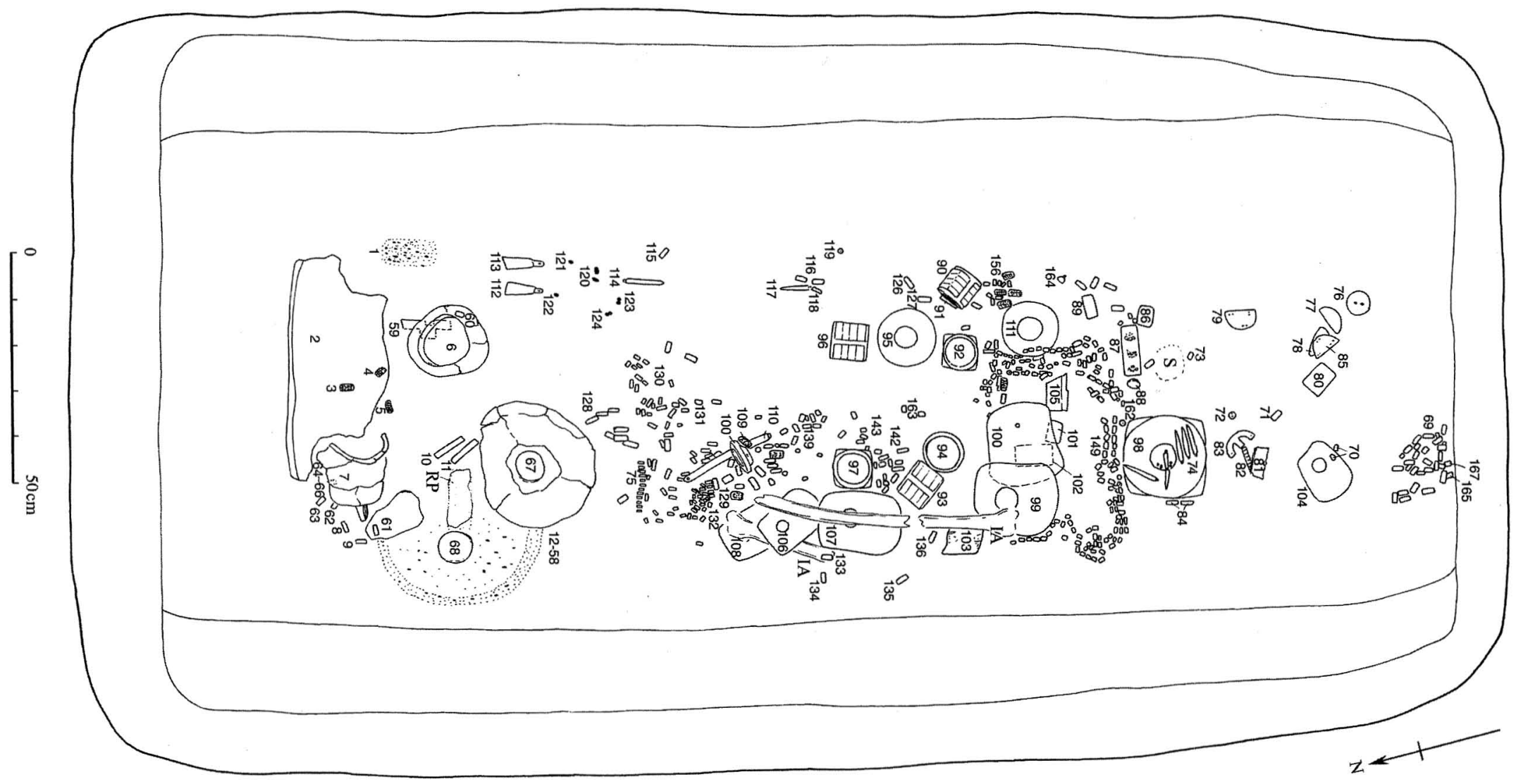

Fig. 5. Plan of excavated burial pit (M12) and grave goods at Fanshan. S: human skull; IA: ivory artifact; RP: red pottery. 1, 68: lacquered woodwork. 2, 6, 7, 67: pottery vessels. 99, 104, 106, 107, 108: stone implements. The burial was wrapped in a silk shroud with a large number of attached jade beads (not numbered individually) and cong (from Institute of Archaeology, Zhejiang Province 2005b:29). 
28 in the middle Yangtze and 5 in the lower Yangtze. The jade and lacquer industries, so well developed in previous phases, are no longer in evidence. The Neolithic cultures of the middle and lower Yangtze apparently continued to decline, until the rise of Early Shang civilization during the Erligang phase (c. 1500 B.C.) in the north.

\section{NEOLITHIC CULTURES OF THE LINGNAN-FUJIAN REGION AND SOUTHWESTERN CHINA}

Contrary to the development of intensive agriculture in the middle and lower Yangtze basins, subsistence strategies in Lingnan-Fujian and southwest China after the early Neolithic continued with a heavy emphasis on fishing and hunting. The first direct evidence for farming appeared only in the late phase of the late Neolithic, after 3500 B.C., apparently as a result of farming dispersal from the Yangtze basin. As with the Yangtze basin, we also divide the Neolithic cultures of the Lingnan-Fujian region and southwest China into four phases.

\section{The Middle Neolithic (8000-5000 B.C.)}

Although some caves continued to be occupied during this phase, for instance Xianrendong, Zengpiyan, and Liyuzui, open settlements now appeared on riverine terraces. Examples include sites of the Dingsishan (Baozitou) culture (Guangxi Team et al. 1998) along the Zuo, You, and Yong rivers in Guangxi. A related cultural assemblage also occurred in northern Viet Nam, here called the Da But culture by Vietnamese archaeologists (Viet 2005). This was followed slightly later by the Gaomiao culture of the middle Yuan basin in Hunan (G. He 2006; Institute of Archaeology, Hunan Province 2000); the Chengbeixi culture (Chen and Yang 1989); as well as the lower layer of the Yuxi site in western Hubei and eastern Chongqing (Zou 2003; Fig. 2). Although settlement locations appear similar to those of the contemporaneous Pengtoushan-Zaoshi and Kuahuqiao cultures of the middle and lower Yangtze, the subsistence patterns of the Lingnan-Fujian region and southwest China remained quite different. There is a virtual absence of direct palaeobotanical evidence for agricultural production, in favor of continuing fishing and hunting. At Dingsishan, no evidence for rice agriculture prior to Dingsishan phase IV has been found so far (Z. Zhao et al. 2005). Although a few rice husks were found at Gaomiao and Chengbeixi, it is still uncertain whether these were local in origin or acquired by exchange.

Aquatic resources in the form of shell middens occur in sites of the Dingsishan and Gaomiao cultures, and many fish and wild animal bones were found in the sites of the Chengbeixi culture and the lower layer of Yuxi. Burial in a crouched or flexed position is also characteristic of these sites. Unlike sites of this period associated with the Yangtze plain cultures, there is no evidence for any textile industry. Both the Gaomiao and Chengbeixi cultures emerged to the north of the Nanling mountain range, and show strong connections with the PengtoushanZaoshi culture of the Dongting Lake alluvial plain. But the origins of these cultures are still uncertain. In Lingnan, south of the Nanling Mountains, only sites of the Dingsishan culture are reported. In the Yun-Gui region of Yunnan, late Palaeolithic occupations continued in Maludong Cave, Mengzi, and Tangzigou, 
Baoshan County (X. Y. Zhang $1991: 109-111)$. Open sites with hunter-gatherer subsistence have also been found in the Xia-Jiang region ${ }^{11}$ of the Three Gorges and western Hubei.

\section{The Early Phase of the Late Neolithic (5000-3500 B.C.)}

This period of maximum postglacial temperature, which provided the background for the development and spread of agriculture in the middle and lower Yangtze basins, also witnessed the spread of a hunter-gatherer economy in the Lingnan-Fujian region and southwest China. Most of the shell middens in the Yuan River basin date from this time. Settlement numbers increased in the XiaJiang region of the Three Gorges and western Hubei, forming a backdrop for the eventual development of a non-agricultural facies of the Daxi culture in western Hubei (or the so-called Exi facies of the Daxi culture) and the Yuxiping culture of Sichuan. Sites of both these cultures produce large quantities of fish remains (Fig. 2).

In the Xia-Jiang region, several lithic workshops were discovered from this phase, such as Yangjiawan in Yichang (B. Lin 1994), Guandukou in Badong (R. Wang 1997), and Honghuatao (Yan 1989a). Large numbers of stone axes, adzes, and chisels were produced by these workshops (C. Zhang 2003:124-125). Very large lithic workshops also occur at Gexinqiao in Baise (Archaeological Team of the Guangxi Zhuang Municipality 2003) and in the first phase at Beidaling in Duan (Q. Lin et al. 2005), both in Guangxi, and at Shilaodun in Yingde, Guangdong (Yingde City Museum 1999; Fig. 2). The shellfishing economy expanded into Lingnan, with shell middens such as Fangcheng in Guangxi (Guangdong Provincial Museum 1961) and Shiweishan and Chenqiaocun in Guangdong (Cultural Relics Committee of Guangdong Province 1961). Some sand dune sites, with pottery but without dense shell midden, such as Xiantouling (Dawan culture) in the estuary of the Zhu (Pearl) River, also appear at this time (Shenzhen City Museum and Department of Archaeology, Zhongshan University 1990), as do early shell midden sites on Hainan Island (Hao and Wang 2003), on several islands off the Fujian coastline (Keqiutou culture) (Chang 1986:231; Fujian Provincial Museum 1991; C. Lin 1973), in the Penghu archipelago, and on Taiwan (early Dabenkeng culture; see Huang 1974). These shell midden and sand dune sites represent the earliest pottery-using cultures of coastal southern China (Fig. 2).

We suggest that these hunter-gatherer cultures might have originated from the later Gaomiao culture, contemporaneous with the Daxi culture in the middle Yuan basin (J. He 1994). The Xiantouling culture in the Zhu estuary is even called the Lingnan facies of the Daxi culture by some researchers, owing to the similarities in pottery style ( $\mathrm{Bu} 1999: 54)$. Farming practices in the LingnanFujian region are not well substantiated, but 10-20 percent of meat consumption in the Daxi culture came from domesticated pigs (J. Yuan 1999:7-8).

\section{The Late Phase of the Late Neolithic (3500-2500 B.C.)}

The late phase of the late Neolithic is marked by the first identified farming dispersal from the middle and lower Yangtze into Lingnan-Fujian. The number of 
shell middens declined in the Yuan River and Xia-Jiang regions, and the lack of continuity (Meng 1997) into later cultures suggests a possible migration from the Qujialing culture of the middle Yangtze. Shell midden and sand dune sites also declined in the Zhu delta of Guangdong and the Min delta of Fujian (Nishitani 1997).

At this time, the Shixia culture (Guangdong Provincial Museum 1978) arose in northern Guangdong, as did the Wusaoling culture (G. He 1997) in western Guangdong and the Xi basin of eastern Guangxi. Shixia and Wusaoling share similarities and both resemble the Fanchengdui culture of the Gan-Bo region (Jiangxi Team of Cultural Relics et al. 1989; Qingjiang Museum 1981) and the Daiziping culture of the Xiang basin. There is a high possibility that the Shixia culture developed from the Fanchengdui, and that the Wusaoling followed the Daiziping (G. He 1997). The Tanshishan culture of the lower Min River, the first rice farming complex in Fujian Province, shows strong relations with the Liangzhu culture of southwestern Zhejiang (Institute of Archaeology, Zhejiang Province, and Cultural Relics Committee of Suichang County 2001; Fig. 2).

Clear evidence suggests that these agricultural societies (Yan 1989b; Yang 1978), such as Shixia, Wusaoling, and Tanshishan, were not indigenous to the Lingnan-Fujian region but spread from the Yangtze. All of these communities have similar settlement patterns, with a large number of house foundations, pits, cemeteries, and craft-specialized workshops. They all grew rice, as in Taiwan (here with foxtail millet) by this time (Tsang et al. 2004). In southwestern China, a Majiayao site in Yingpanshan, Maoxian, northwest Sichuan (Institute of Archaeology, Chengdu City 2002), also supports a hypothesis of southward migration from northwest China (Chen and Yu 2005).

\section{The Terminal Neolithic (2500-2000 B.C.)}

In this phase, the number of settlements dramatically increased in the LingnanFujian region (H. Zhao 1999) and southwest China. Locally, this was the full blossoming of the Neolithic in this area, at a time when regional populations are estimated to have exceeded in size those of the middle and lower Yangtze. Most Shixia (phase III) river terrace sites in Guangdong are typically agricultural, and the distribution of this culture spread northward to the Doupengpo culture of the upper Yuan and $\mathrm{Zi}$ basins (G. He 1997). In Taiwan, during the local middle Neolithic, the number of sites multiplied considerably. Agriculture was well developed and lithic and jade artifacts were exchanged extensively in Taiwan during this phase (Hung 2004, 2005a).

In Guangxi, many new settlements were founded in this phase, which belong to the "Large Shovel (Da Shi Chan) Culture" of local Lingnan archaeologists. Significant quantities of rice have been recovered from Dingsishan phase IV in southern Guangxi (Zhao et al. 2005) and Xiaojin phase II in northern Guangxi (Archaeological Team of the Guangxi Zhuang Municipality and Cultural Relics Committee of Ziyuan County 2004). In southwest China, we see the appearance of numerous large settlements, some defended by hangtu walls, with the emergence of the Baoduncun culture in the Chengdu plain (Z. Jiang et al. 2002). In Yunnan, it has long been believed that the oldest Neolithic sites occur along the 
shoreline of Lake Dian (Xiao 2001; Fig. 2), but recent evidence suggests that these sites date to only ca. 1500 B.C. (Sun 2006:77). So far, the earliest rice remains in Yunnan are from Baiyangcun, where husks and straw are dated c. 2500-2000 B.C. This suggests that the earliest Neolithic assemblages in Yunnan were associated with rice farming, probably as a result of cultural dispersal from outside.

The development of food production may have been the major factor behind in situ population growth in Lingnan-Fujian and southwest China. However, considering the evidence for contemporary decrease of population in the Yangtze basin, it is possible that a southward and westward migration from here needs to be taken into account. Similar explanations can be applied to the seemingly abrupt appearances of the Baoduncun culture (Yu 1997) and the Neolithic of southwestern China.

\section{SUMMARY AND DISCUSSION}

\section{Cultural Evolution in the Middle and Lower Yangtze Valley}

In this article, we have offered a brief review of cultural patterns and settlement history in southern China, integrating new archaeological data into the record of Neolithic sites in the region. Toward the end of the early Neolithic $(14,000-$ 8000 B.C.), sites located on the northern and southern sides of the Nanling mountain range began to reveal cultural differentiation (C. Zhang 2006). The oldest pottery, with only ambiguous evidence for food production, occurred north of the Nanling Mountains. The Pengtoushan-Zaoshi culture (8000-5000 B.c.) of the middle Yangtze Valley appears to descend from this earlier northern pottery tradition. The Pengtoushan-Zaoshi sites, mostly located on riverine terraces, have very early records for pre-domestication food production, possible animal domestication, and a textile industry.

Later, in the early phase of the late Neolithic (5000-3500 в.c.), farming settlements spread gradually along the middle and lower Yangtze Valley. Each region developed its own cultural and economic characteristics, and some large settlements became regional economic-cultural centers. In the following phase, the late phase of the late Neolithic (3500-2500 B.C.), the full domestication of rice advanced rapidly. Material culture traditions in pottery, stone, jade, lacquer, and silk became highly developed, and rank differences in material wealth became more visible. Two nuclear areas, Qujialing-Shijiahe and Liangzhu, appeared in the Two Lakes and Tai Lake regions, respectively. However, regional populations declined suddenly in the terminal Neolithic (2500-2000 в.C.).

Site densities rose at first and then fell from the early through to the terminal Neolithic, but with differing regional trends, in both the middle and lower Yangtze alluvial plains and in the Lingnan-Fujian region. For instance, archaeological survey in the Lixian region ${ }^{12}$ of western Dongtian Lake, northwest Hunan, has recorded 22 middle Neolithic Pengtoushan sites, 39 Daxi sites from the early phase of the late Neolithic, 200 Qujialing-Shijiahe sites from the late phase of the late Neolithic, but only one terminal Neolithic late Shijiahe site. ${ }^{13}$ From the Daxi to the Shijiahe phases, the population increased rapidly, not only in terms of the number of settlements, but also in terms of settlement size. During 
the late phase of the late Neolithic, some settlements had community cemeteries with more than 1000 burials. This was clearly the most prosperous phase in the Yangtze basin Neolithic. In the late Shijiahe phase, population densities in the middle Yangtze basin appear to have collapsed dramatically. Site numbers decreased, and the sites themselves have thin occupation layers. Chinese archaeologists have put forward several hypotheses to explain this pre-Shang collapse, including flooding, northward population movement, or simply a collapse of the social order (H. Lin 1998:501-534).

\section{Northward: Cultural Interaction with the Yellow River Valley}

From the middle until the terminal Neolithic, the middle and lower Yangtze basins formed the nuclear agricultural areas for southern China, as likewise did the Yellow River basin for northern China. During the 4500-year Neolithic time span, the Yangtze appears to have played a more active role in the genesis of agriculture and in the development of cultural interaction between these two nuclear areas.

Although the precise nature of rice cultivation in the early Neolithic is debatable, the evidence for food production in the Pengtoushan sites in the middle Yangtze Valley is clear, and earlier than the evidence for early food production in northern China. In northern China, there is no obvious cultural continuity between the late Palaeolithic small flake tool tradition and the millet-producing early Neolithic Cishan-Peiligang phase (Y. Wang 2003). Therefore, Cohen (2003) has questioned the suggestion of independent farming origins in northern China. Zhu (Y.-P. Zhu 2004) has also suggested that millet cultivation in northern China was a result of regional adaptation to lower temperatures, and was based on a foundation of rice cultivation introduced from the south. At Jiahu, in the Huai Valley, not only have millet and rice remains been found, but also pottery and other artifacts similar to those of both Pengtoushan and Peiligang (Institute of Archaeology, Henan Province 1999:515-518).

In northern China, during the later phase of the middle Neolithic, rice agriculture became a major component of subsistence strategies in central Henan and in the Wei River of central Shanxi in the early phase of the late Neolithic (Yangshao culture), especially in the sites of Hejiacun and Lijiacun in the middle Han Valley. During the terminal Neolithic it spread into northern Shandong (Longshan culture), and later to the Liaodong Peninsula, Korea, and eventually Japan (Yan 1993).

In the early phase of the late Neolithic, jade, lacquer, and silk industries developed in the middle and lower Yangtze and strongly influenced the Yellow River Neolithic cultures. In the late phase of the late Neolithic, when plow cultivation and intensive agriculture developed along the Yangtze, the influence of the Qujialing culture reached central Henan (Cultural Relics and Archaeology Institute of Zhengzhou City 2001), and that of the early Liangzhu reached the Shandong-Jiangsu border (Nanjing Museum 2003). However, these northward flows of influence were reversed during the later stage of the late Neolithic, when the late Dawenkou culture expanded to the Yangtze. Until this time, Neolithic achievements in southern China laid the foundations for the coming rise of Chinese civilization. 


\section{Southward: Cultural Dispersal into the Lingnan-Fujian Region, Southwest China,} and Southeast Asia

The Neolithic agricultural societies of the Yangtze also had a significant impact on the Lingnan-Fujian region, southwest China, and Southeast Asia. During the middle Neolithic, in the Xi Valley (Guangxi), in northern Viet Nam, to the north between Lingnan-Fujian and the lower Yangtze, and in the Xia-Jiang region of the Three Gorges and western Hubei, there appeared an economy based on fishing and shellfishing, quite different from the contemporary predomestication agricultural subsistence of the Yangtze basin. In terms of pottery style and lithic technology, we believe that the Dingsishan culture of the Xi Valley developed from the local cave tradition in Guangxi. The Gaomiao culture in the Yuan Valley of northern Hunan and the Chengbeixi culture of the Xia-Jiang region derived from the Pengtoushan culture in the middle Yangtze, but, for some unknown reason, appear to have discontinued agricultural practices.

At about 7000 years ago, the Gaomiao culture, the Xia-Jiang facies of the Daxi culture, and hunter-gatherer groups in eastern Guangxi all began to spread into southeastern China. Shell midden and sand dune sites henceforth appear on the offshore islands of Fujian and Guangdong, forming the Keqiutou culture of the Fujian coastline, the earlier phase of the Dabenkeng culture of Taiwan, and possibly the Da But culture of northern Viet Nam. Therefore, a hunting-gathering subsistence pattern in the Lingnan-Fujian region, with a reliance on aquatic resources, was the precursor of the Neolithic lifestyle in Southeast Asia.

Following this phase, in the late phase of the late Neolithic, groups began to migrate from the Yangtze basin by a process of agricultural dispersal, forming the rice-farming Tanshishan and Shixia cultures. At the same time, millet-cultivating groups moved southward into northwest Sichuan. All of these migrations and interactions between exogenous agriculturalists and indigenous hunter-gatherers created a new style of prehistoric culture in southern China. Shell middens disappeared, possibly because of climatic deterioration (Chen and Wu 1996; Zhu et al. 1997 : 271).

Later on, during the terminal Neolithic (2500-2000 B.C.), the full bloom of agricultural development occurred in Lingnan-Fujian and southwest China, and this led to a second phase of population outflow, this time into Mainland and Island Southeast Asia. From recent studies, it is evident that cultural expansion occurred from Taiwan into the northern Philippines at this time (Hung 2005a, $2005 b$ ), as did the spread of farming into northern Viet Nam and Thailand (Higham 2002, 2003). This history of human movements reconstructed from archaeological evidence is similar in origin and directionality to the results of linguistic studies (Pejros and Shnirelman 1998). These movements of farming technologies and subsistence strategies respectively marked the spread of the Austroasiatic and Austronesian-speaking peoples (Bellwood 1991, $2005: 111-142$ ).

In the terminal Neolithic, the cultures of Lingnan-Fujian transmitted cultural influence into the middle and lower Yangtze basins. Based on similarities in ceramics, the Doupengpo culture of the upper Yuan and $\mathrm{Zi}$ basins has a Lingnan origin. Geometric impressed pottery, a major Lingnan characteristic, also occurs in the late Shijiahe culture of the middle Yangtze, as later in the Maqiao culture of 
the Jiang-Zhe region, and other contemporaneous Yangtze cultures that laid the foundations for the Bronze Age in southern China.

Overall, during the middle and late Neolithic, with a developing interest in food production, the foci of major development shifted from the Nanling Mountains, to the middle and lower Yangtze alluvial plain, and then again southward to the Lingnan-Fujian region and the Yungui plateau in the terminal Neolithic. These shifting regions of intensive cultural development and population growth in southern China all had significant influences on the prehistory of China and surrounding areas.

\section{CONCLUSIONS}

Our synthesis is consistent with K. C. Chang's Lungshanoid hypothesis (Chang 1964, 1987, 1994), Bellwood's farming dispersal theory (Bellwood 1991, 2005), and Yan's work on the spread of food production in eastern Asia (Yan 1998). All of these authors suggest that the southward dispersal of agriculture and pottery making from the Yangtze Valley was a significant event in the history of human migration. New archaeological evidence in the region suggests that there were two stages in the spread of farming in the southern Chinese Neolithic. Before the spread there was a long period of pre-domestication cultivation, and the spread of food production lagged behind the earliest spread of pottery production (Zhang and Hung 2008).

Both southern and northern China played significant roles in the development of East Asian prehistory and civilization. Because of their different geographical locations and natural environments, and their different histories of interaction and external links since the Pleistocene, each had a different impact. The formation of Han Chinese civilization occurred in the Yellow River Valley, in contact with the northern and northwestern regions of China during the late Neolithic. Southern China was not as well placed in this matter, and no major civilization developed there in prehistoric times. As a result, the historical significance of southern China has long been overlooked. Many new discoveries and more detailed studies of long-known sites are changing the archaeological profile of southern China, bringing new evidence to bear on archaeological theories of East Asian archaeology and even contributing to global studies of agricultural origins and dispersal.

\section{ACKNOWLEDGMENTS}

We are grateful to Professor Peter Bellwood of Australian National University at Canberra, Dr. Laura Junker of University of Illinois at Chicago, and two anonymous reviewers for giving us invaluable comments on this manuscript.

\section{NOTES}

1. The subdivision of China into north and south has been a significant concept throughout history. The division is clearly marked by variations in climate, natural vegetation, soils and crops (Chang 1986:1-3). In this article, "southern China" refers to the region between the Qinling 
Mountains-Huai River Valley and the southern national boundary with the countries of Mainland Southeast Asia.

2. In the following discussion, the Lingnan-Fujian region refers to the provinces of Guangdong, Guangxi, and Fujian.

3. This region includes Sichuan, Yunnan, and Guizhou provinces.

4. Recent studies have divided the "Daxi Culture" by regions and phases (Meng 1997; Pei 1999; X. Q. Zhang 1992).

5. The Two Lakes region includes the Jianghan plain and the Dongting Lake plain (see Fig. 3).

6. The $\mathrm{Su}-\mathrm{Wan}$ region includes the $\mathrm{Su}-\mathrm{Wan}$ and Chao Lake plains and the Ningzhen area (see Fig. 3).

7. The Gan-Po region includes the Gan Valley and the Poyang Lake plain (see Fig. 3)

8. The Jiang-Zhe region includes the Yangtze delta (see Fig. 3).

9. The Mid-Han River region includes the Nanyang basin, Xiangfan Valley, and Suizao corridor (see Fig. 3).

10. For example, the pottery vessels unearthed from Pit No. 2 (H2) at Beiyinyangying include three-legged gui, some with incised designs similar to counterparts in the late Dawenkou culture in Shandong (Nanjing Museum 1993:87-88, 166-167).

11. The Xia-Jiang region includes the Three Gorges and western Hubei (see Fig. 3).

12. Lixian is a county of 2075 sq. $\mathrm{km}$ located in northwestern Hunan. Current population is 880,000 , distributed in 32 towns.

13. For more details on changes in site numbers for each Yangtze Valley region, see C. Zhang 2003.

\section{REFERENCES CITED}

Archaeological Team of the Guangxi Zhuang Municipality

2003 Guang xi bai se shi ge xin qiao xin shi qi shi dai yi zhi (The Neolithic Gexinqiao Site at Baise, Guangxi). Kao Gu (Archaeology) 2003(12):1-5 (in Chinese).

Archaeological Team of the Guangxi Zhuang Municipality and Cultural Relics CommitTEE OF ZiYuAN COUNTY

2004 Guang xi zi yuan xian xiao jin xin shi qi shi dai yi zhi fa jue jian bao (Report on the archaeological excavation of Xiaojin Site in Ziyuan County, Gangxi). Kao Gu (Archaeology) 2004(3): 7-30 (in Chinese).

Archaeological Team of the Peking University

1989 He nan deng zhou ba li gang yi zhi fa jue jian bao (A brief report on the excavation at Baliganag, Dengzhou). Wen Wu (Cultural Relics) 9:31-45 (in Chinese).

Bellwood, Peter

1991 The Austronesian dispersal and the origins of language. Scientific American 265: 88-93.

2005 First Farmers - The Origins of Agricultural Societies. London: Blackwell.

Bu, GONG

1999 Huan zhu jiang kou xin shi qi shi dai wan qi kao gu xue yi cun de bian nian yu pu xi (Chronologies and genealogies of the late Neolithic remains at the outlet of the Pearl River). Wen $W u$ (Cultural Relics) 11:48-56 (in Chinese).

Chang, KWANG-CHIH

1964 Prehistoric and early historic culture horizons and traditions in South China. Current Anthropology 5(5):359, 369-375.

1986 The Archaeology of Ancient China, 4th ed. New Haven and London: Yale University Press.

1987 Zhong guo dong nan hai an kao gu yu nan dao yu zu qi yuan wen ti (Archaeology of coastal southeast China and the issue of Austronesian origins). Nan Fang Min $\mathrm{Zu} \mathrm{Kao} \mathrm{Gu}$ (Archaeology of southern people) $1: 13$ (in Chinese).

1994 Zhong guo dong nan hai an kao gu yu nan dao yu zu qi yuan wen ti (Archaeology of coastal southeast China and the issue of Austronesian origins), in Ancient Cultures of South China and Neighbouring Regions: 311-320, ed. Tang Chung. Hong Kong: Centre for Chinese Archaeology and Art, ICS, Chinese University of Hong Kong (in Chinese).

Chen, Jian, And Chun Yu

2005 Chang jiang shang you di qu wen ming hua jin cheng xue shu tao lun hui ji yao (A summary of the symposium on the civilizing course in the upper Yangtze River Valley). Kao Gu (Archaeology) 5:89-93 (in Chinese). 
Chen, Jie, AND JiAn-Min Wu

1996 Tai hu di qu liang zhu wen hua shi qi de gu huan jing (The ancient environment around the Taihu area during the stage of Liangzhu Culture), in Dong Fang Wen Ming Zhi Guang (The Light of Oriental Civilization): 306-318, ed. Xu Hu-ping. Haikou: Hainan International News Center Press (in Chinese).

CHEN, SHI-LONG

1999 Gui lin miao yan yi zhi de fa jue yu yan jiu (Excavations at Miaoyan Cave, Guilin), in Zhong Shi Qi Wen Hua Ji You Guan Wen Ti Yan Tao Hui Lun Wen Ji (Treatises of International Conference on Mesolithic Culture): 150-164, ed. Yingde City Museum, Anthropology Department of Zhongshan University, and Guandong Provincial Museum. Guangzhou: Guangdong People Publishing House Press (in Chinese).

Chen, Zhen-yu, and QuAN-XI YANG

1989 Hu bei yi du cheng bei xi yi zhi (Chengbeixi Site in Yidu, Hubei). Shi Qian Yan Jiu (Prehistory) 85-94 (in Chinese).

Cohen, David JoeL

2003 Microblades, pottery, and the nature and chronology of the Palaeolithic-Neolithic transition in China. The Review of Archaeology (Fall): 21-36.

Crawford, Gary w., and Chen Shen

1998 The origins of rice agriculture: recent progress in East Asia. Antiquity 72 (278):858-866.

Cultural Relics Committee of Guangdong Province

1961 Guang dong chao an de bei qiu yi zhi (The shell midden sites at Chaoan, Guangdong). Kao Gu (Archaeology) 11:577-584 (in Chinese).

Department of Archaeology, Peking University, Institute of Archaeology, Hubei ProvINCE, AND Jingzhou Musuem, Hubei PRovince

1992 Shi jia he yi zhi diao cha bao gao (An investigation at Shijiahe sites). Southern Ethnology and Archaeology 5:213-294. Chengdu: Sichuan Science Technology Press (in Chinese).

Fu, Xian-guo, Zhan-wu He, Zhao-ming Xiong, and HaO-tian Wang

2001 Gui lin di qu shi qiang wen hua mian mao lun kuo chu xian (An aspect of the prehistoric cultures in Guilin region). Zhong Guo Wen Wu Bao (China Antiquity News) (April 4): 1 (in Chinese).

Fuller, Dorian, Emma Harvey, AND Ling Qin

2007 Presumed domestication? Evidence for wild rice cultivation and domestication in the fifth millennium BC of the Lower Yangtze region. Antiquity: 316-331.

Fujlan Provincial Museum

1991 Fu jian ping tan ke qiu tou yi zhi fa jue jian bao (A brief of the excavation at Keqiutou site, Pingtan, Fujian). Kao Gu (Archaeology) 7:581-600 (in Chinese).

\section{Guangdong Provincial Museum}

1961 Guang dong dong xing xin shi qi shi dai bei qiu yi zhi (Neolithic shell middens in Dongxing, Guangdong). Kao Gu (Archaeology) 12:644-649 (in Chinese).

1978 Guang dong qu jiang shi xia mu zang fa jue jian bao (A brief of the excavation at Shixia Site, Qujiang, Guangdong). Wen Wu (Cultural Relics) 7:1-15 (in Chinese).

Guangxi Team, Institute of Archaeology, CASS (Chinese Academy of Social Sciences), Archaeological Team of the Guangxi Zhuang Municipality, Nanning City Museum

1998 Guang xi yong ning ding si shan yi zhi de fa jue (The excavation of Dingsishan Site in Yongning, Guangxi). Kao Gu (Archaeology) 11:11-33 (in Chinese).

HaO, Si-De, AND WANG, DA-XIN

2003 Hai nan kao gu de hui gu yu zhan wang (The review and expectancy of Hainan Archaeology). Kao Gu (Archaeology) 4:3-11 (in Chinese).

He, GANG

1997 Nan ling nan bei di qu xin shi qi shi dai zhong wan qi wen hua de guan xi (Cultural relations of the middle and late Neolithic between northern and southern Nanling Mountain Range), in Zhong Guo Kao Gu Xue Xue Hui Di Jiu Ci Nian Hui Lun Wen Ji (The Ninth Annual Conference of Chinese Archaeology Association, 1993): 175-194. Beijing: Cultural Relics Publishing House Press (in Chinese).

2006 Hu nan hong jiang gao miao yi zhi fa jue huo zhong da fa xian (Great discovery from the excavation of Gaomiao Site, Hongjiang, Hunan). Zhong Guo Wen Wu Bao (China Antiquity News) (Jan. 6): 1 (in Chinese). 
He, JiE-JuN

1994 Huan zhu jiang kou de shi qian cai tao yu da xi wen hua (Prehistoric painted pottery in the estuary of Pearl River and Daxi Culture), in Nan Zhong Guo Ji Lin Jin Di Qu Gu Wen Hua Yan Jiu (Ancient Cultures of South China and Neighbouring Regions: Essays in Honor of Professor Cheng Te-K'un on the Occasion of the Sixtieth Anniversary of his Academic Career): 71-78, ed. The Center for Chinese Archaeology and Art of the Chinese University of Hong Kong. Hong Kong: The Chinese University of Hong Kong Press (in Chinese).

He, NaI-HaN

1988 Ling nan di qu jiu shi qi shi dai xiang xin shi qi shi dai de guo du ji qi you guan de ji ge wen ti (The transition from Palaeolithic to Neolithic Age in Lingnan and its related questions), in Zhong Guo Kao Gu Xue Hui Di Wu Ci Nian Hui Lun Wen Ji (Papers on the Fifth Annual Meeting of Chinese Archaeology Association): 158-166. Beijing: Cultural Relics Publishing House Press (in Chinese).

Higham, Charles

2002 Early Cultures of Mainland Southeast Asia. London: Thames and Hudson.

2003 Language and farming dispersals: Austroasiatic languages and rice cultivation, in Examining the Language/Farming Dispersal Hypothesis: 223-232, ed. Peter Bellwood and Colin Renfrew. Cambridge: McDonald Institute for Archaeological Research.

HuANG, SHI-QIANG

1974 Tai nan xian gui ren xiang ba jia cun yi zhi diao cha (Archaeological survey at Bajiacun Site, Guiren, Tainan). Bulletin of the Department of Anthropology 35/36:62-68. Taipei: Department of Archaeology and Anthropology, National Taiwan University, Taipei (in Chinese).

\section{Hunan Provincial Museum}

1982 Hu nan an xiang xian tang jia gang xin shi qi shi dai yi zhi (The Neolithic Tangjiagang site in Anxian, Hunan). Kao Gu (Archaeology) 4:341-354 (in Chinese).

Hung, HSIAO-Chun

2004 A sourcing study of Taiwan stone adzes. Bulletin of the Indo-Pacific Prehistory Association $24: 57-70$.

$2005 a$ The culture interaction between Taiwan and adjacent islands-the origins and dispersal of Austronesian-speaking peoples, in The Archaeology of Southeast Coastal Islands of China Conference: 249-269, ed. Jonas Chung-yu Chen and Jian-Guo Pan. Taiwan: Mazu County Government (in Chinese).

$2005 b$ Neolithic interaction between Taiwan and northern Luzon. Journal of Austronesian Studies $1(1): 108-133$

Institute of Archaeology, Anhui Province

1989 An hui han shan ling jia tan xin shi qi shi dai mu di fa jue jian bao (Excavation at the Neolithic Lingjiatan Site in Hanshan). Wen Wu (Cultural Relics) 4:1-35 (in Chinese).

1999 An hui sheng han shan xian ling jia tan yi zhi di san ci fa jue jian bao (Report on the third excavation in the Neolithic Lingjiatan Site, Anhui Province). Kao Gu (Archaeology) 11:112 (in Chinese).

2006 Ling jia tan (Excavation at the Lingiatan Site). Beijing: Cultural Relics Publishing House Press (in Chinese).

Institute of Archaeology, CASS (Chinese Academy of Social Sciences)

1974 Fang she xing tan su ce ding nian dai bao gao (Report on radiocarbon dates: part 3). Kao Gu (Archaeology) 5:333-338 (in Chinese).

1977 Fang she xing tan su ce ding nian dai bao gao (Report on radiocarbon dates: part 4). Kao Gu (Archaeology) 3:200-204 (in Chinese).

1978 Fang she xing tan su ce ding nian dai bao gao (Report on radiocarbon dates: part 5). Kao Gu (Archaeology) 4:243, 280-287 (in Chinese).

1997 Fang she xing tan su ce ding nian dai bao gao (Report of radiocarbon dates: part 24). Kao Gu (Archaeology) 7:35-38, 52 (in Chinese).

Institute of Archaeology, CASS (Chinese Academy of Social Sciences), Archaeological Team of The Guangxi Zhuang Municipality, Zengpiyan Site Museum in Guilin, Archaeological Team of the Guilin City

2003 Guilin Zengpiyan (Zengpiyan-A Prehistoric Site in Guilin). Beijing: Cultural Relics Publishing House Press (in Chinese). 
Institute of Archaeology, Chengdu City

2002 Si chuan mao xian ying pan shan yi zhi shi jue bao gao (Excavation at the Yingpanshan Site in Maoxian, Sichuan), in Cheng Du Kao Gu Fa Xian (Archaeological Discoveries in Chengdu): 1-77, ed. Institute of Archaeology, Chengdu City. Beijing: Science Press (in Chinese).

Institute of Archaeology, Henan Province

1989 Xi Chuan Xia Wang Gang (Xiawanggang in Xichuan). Beijing: Cultural Relics Publishing House Press (in Chinese).

1999 Wu Yang Jia Hu (Jiahu in Wuyang). Beijing: Science Press (in Chinese).

Institute of Archaeology, Hunan Province

1996 Hu nan Li xian Meng xi Ba Shi Dang xin shi qi shi dai zao qi yi zhi fa jue jian bao (Report on the archaeological excavation of the early Neolithic Site at Bashidang, Mengxi, Lixian, Hunan). Wen Wu (Cultural Relics) 12:26-39 (in Chinese).

1999 Li xian cheng tou shan gu cheng zhi 1997-1998 nian du fa jue jian bao (Report on the archaeological excavation of the Chengtoushan Site at Lixian, 1997-1998). Wen Wu (Cultural Relics) 6:4-17 (in Chinese).

2000 Hu nan qian yang gao miao yi zhi fa jue jian bao (A brief of the excavation at Gaomiao Site, Qianyang, Hunan). Wen Wu (Cultural Relics) 4:4-23 (in Chinese).

2006 Peng Tou Shan Yu Ba Shi Dang (Pengtoushan and Bashidang). Beijing: Science Press (in Chinese).

2007 Li Xian Cheng Tou Shan-Xin Shi Qi Shi Dai Yi Zhi Fa Jue Bao Gao (Report on the Excavation at Neolithic Chengtoushan Site, Li Xian). Beijing: Cultural Relics Publishing House Press (in Chinese).

Institute of Archaeology, Nanjing Museum, Yangzhou Museum, and Gaogou Cpam

1997 Jiang su gao you zhou bei Guo yi zhi fa jue bao gao (The excavation of Zhoubeiguo Site in Gaoyou, Jiangsu). Kao Gu Xue Bao (Acta Archaeologica Sinica) 4:481-514 (in Chinese).

Institute of Archaeology, Nanjing Museum, Yangzhou Museum, and Xinghua Museum

1995 Jiang su xing hua dai jia she nan dang yi zhi (Excavation of the Nandang Site at Daijiashe, Xinghua, Jiangsu). Wen Wu (Cultural Relics) 1995(4) : 16-31 (in Chinese).

Institute of Archaeology, Zhejiang Province

2003 Yaoshan. Beijing: Cultural Relics Publishing House (in Chinese).

2005a Liang Zhu Yi Zhi Qun (Liangzhu Sites). Beijing: Cultural Relics Publishing House Press (in Chinese).

2005b Fanshan. Beijing: Cultural Relics Publishing House Press (in Chinese).

Institute of Archaeology, Zhejiang Province, and Cultural Relics Committee, Suichang COUNTY

2001 Hao Chuan Mu Di (Haochuan Cemetery). Beijing: Cultural Relics Publishing House Press (in Chinese).

Institute of Archaeology, Zhejiang Province and Xiaoshan Museum

2004 Киа Hu Qiao (The Excavations at Kuahuqiao Site). Beijing: Cultural Relics Publishing House Press (in Chinese).

Institute of Archaeology, Zhengzhou City

2001 Zheng Zhou Da He Cun (Report on the Archaeological Excavation of the Dahecun Site in Zhengzhou). Beijing: Science Press (in Chinese).

JiANG, Le-Ping, AND Li LiU

2006 New evidence for the origins of sedentism and rice domestication in the Lower Yangzi River, China. Antiquity 80:355-361.

Jiang, Zhang-Hua, Wang Yi, AND Zhang QING

2002 Cheng du ping yuan xian qin wen hua chu lun (The pre-Qin Cultures of Chengdu Plain). Kao Gu Xue Bao (Acta Archaeologica Sinica) 1:1-22 (in Chinese).

Jiangxi Provincial Museum

1976 Jiang xi wan nian da yuan xian ren dong dong xue yi zhi di er ci fa jue bao gao (Appendix in report of the secondary excavation at Xianrendong Cave, Dayuan, Wannian, Jiangxi). Wen $W u$ (Cultural Relics) 12:23-35 (in Chinese).

Jiangxi Team of Cultural Relics, Qingjiang Museum, and Department of Archaeology, ZHONGSHAN UNIVERSITY

1989 Qing jiang fan cheng dui yi zhi fa jue jian bao (Report on the excavation of Fanchengdui Site in Qingjiang). Kao Gu Yu Wen Wu (Archaeology and Cultural Relics) 2:20-40 (in Chinese). 
LiN, BANG-CUN

1994 Yi chang yang jia wan yi zhi de zhong yao kao gu fa xian he yan jiu jie guo (The important discoveries from Yangjiawan Site, Yichang). Zhong Guo Wen Wu Bao (China Antiquity News) (Oct. 23): 3 (in Chinese).

LiN, ChaO-Qi

1973 Jin men fu guo dun bei zhong yi zhi (Fuguodun shell midden in Jinmen). Bulletin of the Department of Anthropology 33/34:36-38. Taipei: Department of Archaeology and Anthropology, National Taiwan University, Taipei (in Chinese).

Lin, Hua-Dong

1998 Liang Zhu Wen Hua Yan Jiu (Study on the Liangzhu Culture). Zhejian: Zhejian Education Press (in Chinese).

Lin, Qiang, Xie Guang-Wei and Ning Yong-Qin

2005 Guang xi bei da ling yi zhi kao gu fa jue qu de zhong yao cheng guo (Significant discoveries from Beidaling Site, Guangxi). Zhong Guo Wen Wu Bao (China Antiquity News) (Dec. 2): 1 (in Chinese).

Longqiuzhuang Archaeological Team

1999 Long Qiu Zhuang-Jiang Huai Dong Bu Xin Shi Qi Shi Dai Yi Zhi Fa Jue Bao Gao (Report on the Excavation of Longqiuzhuang Site in Eastern Jianghuai). Beijing: Science Press (in Chinese).

Meng, Hua-Ping

1997 Chang Jiang Zhong You Shi Qiang Wen Hua Jie Gou (Prehistoric Cultural Structures in the Mid-Yangtze River Basin). Wuhan: Chang Jian Wen Yi Press (in Chinese).

Mou, Yong-Kang, and ZhaO-Lin Song

1981 Jiang zhe de shi li he po tu qi-shi lun wo guo li geng de qi tuan (Stone plows and earthbreaking implements from Jiangzhe). Nong Ye Kao Gu (Agricultural Archaeology) 2:75-84 (in Chinese).

NAKAMURA, SHIN-ICHI

2000 Recent discussions on the origin of rice farming in China. Bulletin of Japan Society for Chinese Archaeology 10:1-11 (in Japanese).

Nanjing Museum

1993 Bei Yin Yang Ying-Xin Shi Qi Shi Dai Ji Shang Zhou Shi Ji Yi Zhi Fa Jue Bao Gao (Report on the Archaeological Excavation of the Beiyinyangying Site-From Neolithic Age and Sang to Zhou Civilizations). Beijing: Cultural Relics Publishing House Press (in Chinese).

2003 Hua Ting-Xin Shi Qi Shi Dai Mu Di Fa Jue Bao Gao (Report on the Archaeological Excavation of the Huating Site-A Neolithic Cemetery Site). Beijing: Cultural Relics Publishing House Press (in Chinese).

National Bureau of Cutural Relics, ed.

2000 Jiang su jin tan san xing cun yi zhi (Sanxingcun Site in Jintan, Jiangsu), in 1998 Zhong Guo Zhong Yao Kao Gu Fa Xian (Important Archaeological Discoveries in China, 1998): 1119. Beijing: Cultural Relics Publishing House Press (in Chinese).

Nishitani, Masaru

1997 Neolithic cultures in Coastal Southeast China. Bulletin of National Museum of Japanese History 70:1-56 (in Japanese).

Pei, An-Ping

1992 An xiang xian tang jia gang xin shi qi shi dai yi zhi (The Neolithic Tangjiagang site in Anxian, Hunan), in Annual of Chinese Archaeology-1991:251-252. Beijing: Cultural Relics Publishing House Press (in Chinese).

1998 Li xian Ba Shi Dang yi zhi chu tu da liang zhen gui wen wu (Precious relics from the excavation of the Bashidang site in Lixian). Zhong Guo Wen Wu Bao (China Antiquity News) $10: 1$ (in Chinese).

1999 Xiang bei dong ting hu di qu xin shi qi wen hua xu lie de zai yan jiu (Rethinking the cultural sequence in the Dongtinghu region of northern Hunan), in Zhong Guo Kao Gu Xue Kua Shi Ji De Hug Gu Yu Qian Zhan (Past and Future of Cross-Century of China's Archaeology): 190-198, ed. Zhang Zhong-Pei and Xu Zo-yun. Beijing: Science Press (in Chinese).

2000 Chang jiang zhong you 7000 nian yi qian de dao zuo nong ye he tao qi (Rice agriculture and pottery making at the middle reaches of the Yangtze River 7000 B.P.), in Dao Zuo Tao Qi He Du Shi De Qi Yuan (The Origins of Rice Agriculture, Pottery and Cities): 81-96, ed. Wen-ming Yan and Yoshinori Yasuda. Beijing: Cultural Relics Publishing House Press (in Chinese). 
Pejros, Ilia, and Victor Shnirelman

1998 Rice in Southeast Asia: A regional interdisciplinary approach, in Archaeology and Language 2:379-389, ed. R. Blench and M. Spriggs. London: Routledge.

QingJiang Musuem

1981 Qing jiang fan cheng dui yi zhi shi jue (The excavation at Fanchengdui, Qingjiang), in Kao Gu Xue Ji Kan (Papers on Chinese Archaeology) 1:82-87. Beijing: China Social Sciences Press (in Chinese).

RUDDIMAN, WILLIAM

2005 How did humans first alter global climate? Scientific American (March): 46-53.

Ruddiman, William, Zheng-Tang Guo, and Hai-Ban Wu

In press Early rice farming and anomalous methane trends. Quaternary Science.

Shenzhen City Museum, and Department of Archaeology, Zhongshan University

1990 Shen zhen shi da peng xian tou ling sha qiu yi zhi fa jiu jian bao (A brief of the excavation at Xiantouling Site, Shenzhen). Wen Wu (Cultural Relics) 11:1-11 (in Chinese).

Sun, HuA

2006 Xi nan kao gu de xian zhuang yu wen ti (Archaeology in Southwest China and its related problems). Nan Fang Wen Wu (Southern Cultural Relics) 3:77 (in Chinese).

Tsang, Cheng-Hwa, Kuang-Ti Li, and Cheng-Yi Chu

2004 Tai Nan Ke Xue Gong Ye Yuan Qu Dao Ye Yi Zhi We Hua Ru Bao Cun Qu Bu Fen Qiang Jiu Kao Gu Ji Hua Qi Mo Bao Gao (Report on the Archaeological Excavation of the Daoye Site in Tainan Science Park). Taipei: Academia Sinica (in Chinese).

VIET, NGUYEN

2005 The Dat But Culture: Evidence for cultural development in Vietnam during the middle Holocence. Bulletin of the Indo-Pacific Prehistory Assoication 25:89-92.

WANG, RAN

1997 Ba dong guan du kou xin shi qi shi dai shang zhou ji han dai yi zhi (Guandukou Site in Badong-A Neolithic, Shang, Zhou and Han Site), in Annual of Chinese Archaeology1995: 182-183. Beijing: Cultural Relics Publishing House Press (in Chinese).

WANG, WEI-DA

1984 He mu du he zeng pi yan tao pian re shi guang nian dai de ce ding (T.L. Dating of the potsherds from Hemudu and Zengpiyan), Kao Gu Xue Ji Kan (Papers on Chinese Archaeology) 4:321-327. Beijing: China Social Sciences Press (in Chinese).

Wang, You-Ping

2003 Wan gang xin shi mo zhi quan xin shi chu hua nan yu hua bei shu qi ji shu de fa zhan (The development of manufacturing techniques on lithic tools from the late Pleistocene to early Holocene in southern and northern China). Paper given at Prehistoric Archaeology of South China and Southeast Asia-An International Conference on the 30th Anniversary of the Discovery of the Zengpiyan Assemblage, December 11-14 (in Chinese).

2005 Zhong Guo Yuan Gu Ren Lei Wen Hua De Yuan Liu (Roots of Pleistocene Hominids and Cultures in China). Beijing: Science Press (in Chinese).

Xiao, Ming-Hua

2001 Yun nan kao shu lue (A brief of Yunnan Archaeology). Kao Gu (Archaeology) 12:2-15.

YAN, WEN-MING

1989a Zhong guo xin shi qi shi dai ju luo xing tai de kao cha (Settlement patterns of Chinese Neolithic Age), in Qing Zhu Su Bing Qi Kao Gu Wu Shi Wu Nian Lun Wen Ji (Essays in Celebration of Prof. Su Bing-qi's Fifty-Five Years as an Archaeologist). Beijing: Cultural Relics Publishing House Press (in Chinese).

$1989 b$ Zai lun dao zuo nong ye de qi yuan (Rethink the origins of rice agriculture). Nong Ye Kao Gu (Agricultural Archaeology) 2:72-83 (in Chinese).

1993 Dong bei ya nong ye de fa sheng yu chuan bo (The origin and dispersal of agriculture in Northeast Asia). Nong Ye Kao Gu (Agricultural Archaeology) 3:37-44 (in Chinese).

1997 Wo guo dao zuo qi yuan yan jiu de xin jin zhan (New progress on the study of agricultural origin in our country). Kao Gu (Archaeology) 9:71-76 (in Chinese).

1998 Zhong guo dao zuo nong ye de qi yuan (The origin of rice agriculture in China), in Shi Qian Kao Gu Lun Ji (Papers on Prehistoric Archaeology): 362-384. Beijing: Science Press (in Chinese). 
YANG, SHI-TING

1978 Tan tan shi xia fa xian de zai pei dao yi ji (Remains of cultivated rice in Shixia). Wen $W u$ (Cultural Relics) 7:23-28 (in Chinese).

Yingde City Museum

1999 Ying de sha kou shi lao dun yi zhi (The Shilaodun Site of Shakou in Yingde), in Ying De Shi Qian Kao Gu Bao Gao (Archaeological Reports of Prehistoric Sites in Yingde): 123-230. Guangzhou: Guangdong People Press (in Chinese).

You, XIU-LING

1996 Liang zhu wen hua yu dao de sheng chan, in Wen Ming De Shu Guang-Liang Zhu Wen Hua (Dawn of Civilization-Liangzhu Culture): 143-150. Hangzhou: Zhejiang People Press (in Chinese).

Yu, WeI-ChaO

1997 San xing dui shu wen hua yu san miao wen hua de guan xi ji qi chong bai nei rong (The Shu Culture at Sanxingdui: Its relationship with the Tri-Miao Culture and its worship). Wen Wu (Cultural Relics) 5:34-41 (in Chinese).

YUAN, JIA-RONG

1996 Hu nan dao xian yu chan yan yi zhi (Yuchanyan Cave site in Daoxian, Hunan). Li Shi Yue Kan (Historical Monthly) 6:50-51 (in Chinese).

2000 Hu nan dao xian yu chan yan yi wan nian yi qian de dao gu he tao qi (Rice and pottery 10,000 B.P. at Yuchanyan, Daoxian County, Hunan Province), in Dao Zuo Tao Qi He Du Shi De Qi Yuan (The Origins of Rice Agriculture, Pottery and Cities): 31-41, ed. Wen-ming Yan and Yoshinori Yasuda. Beijing: Cultural Relics Publishing House Press (in Chinese).

YUAN, JING

1999 Lun zhong guo xin shi qi shi dai ju min huo qu rou shi zi yuan de fang shi (Man's meatacquiring patterns in Neolithic China). Kao Gu Xue Bao (Acta Archaeologica Sinica) 1:1-22 (in Chinese).

YuAn, Si-Xun, Li Kun, And Jia-Rong Yuan

1997 Applications of AMS Radiocarbon Dating in Chinese Archaeological Studies, in Application of Accelerators in Research and Industry: 392, ed. J. I. Duggan and I. I. Morgan. New York: AIP Press.

ZHANG, CHI

1997 The rise of urbanism in the middle and lower Yangtze River Valley. Bulletin of the IndoPacific Prehistory Association 16:63-67.

$2000 a$ Jian lun nan zhong guo di qu xin shi qi shi dai zao qi wen hua (A brief of the early Neolithic in southern China), in Zhong Guo Kao Gu Xue Kua Shi Ji De Hug Gu Yu Qian Zhan (Past and Future of Cross-Century of Chinese Archaeology): 190-198, ed. Zhang zhong-pei and $\mathrm{Xu} \mathrm{Zo-yun.} \mathrm{Beijing:} \mathrm{Science} \mathrm{Press} \mathrm{(in} \mathrm{Chinese).}$

$2000 b$ Jiang xi wan nian zao qi tao qi he dao shu zhi gui shi yi cun (Pottery and the silicified rice in Wannian County, Jiangxi Province), in Dao Zuo Tao Qi He Du Shi De Qi Yuan (The Origins of Rice Agriculture, Pottery and Cities): 43-50, ed. Wen-ming Yan and Yoshinori Yasuda. Beijing: Cultural Relics Publishing House Press (in Chinese).

2000 c Da xi bei yin yang ying he xue jia gang de shi qi yu qi gong ye (The lithic and jade industries in Daxi, Beiyinyangying and Xuejiagang Cultures), in Kao Gu Xue Yan Jiu (Archaeological Study) 4:55-76, ed. Peking University. Beijiang: Science Press (in Chinese).

2003 Chang Jiang Zhong Xia You Di Qu Shi Qian Ju Luo Yan Jiu (Prehistoric Settlement Pattern of the Mid and Lower Yangtze River Basin). Beijing: Cultural Relics Publishing House Press (in Chinese).

2006 Zhong guo nan fang de zao qi tao qi (Early pottery in southern region of China), in $G u$ Dai Wen Ming (Ancient Civilizations) Vol. 5:1-16, ed. Research Center of Ancient Civilizations, Department of Archaeology, Peking University. Beijing: Peking University (in Chinese).

Zhang, Chi, and Hsiao-Chun Hung

2008 Zhong guo hua nan ji qi lin jin di qu de xin shi qi shi dai cai ji yu lie wen hua (The Hunter-gatherers in Southern China and its adjacent regions during the Neolithic). Kao Gu Xue Yan Jiu (Archaeology Studies) 7: 415-434, ed. Department of Archaeology, Peking University (in Chinese).

Zhang, Chi, AND Shi-Zhong LiU

1996 Xian ren dong yu diao tong huan yi zhi fa jue shu yao (The brief of excavations at Xianrendong and Diaotonghuan Caves). Li Shi Yue Kan (Historical Monthly) 6:47-49 (in Chinese). 
ZHANG, JING-GUO

1991 An hui han shan ling jia tan xin shi qi shi dai mu di de er ci fa jue de zhu yao shou huo (A brief report on the second excavation in Neolithic Lingiiatan Site, Anhui Province). Wen Wu Yen Jiu (Study of Cultural Relics) 7:258, 259-267 (in Chinese).

ZHANG, WeN-XU

2000 Shui dao de shuang feng ru tu gu dao te zheng he zai pei shui dao de qi yuan (The bipeak-tubercle structure of rice, features of ancient rice and the origin of rice plantation), in Dao Zuo Tao Qi He Du Shi De Qi Yuan (The Origins of Rice Agriculture, Pottery and Cities): 115-127, ed. Wen-ming Yan and Yoshinori Yasuda. Beijing: Cultural Relics Publishing House Press (in Chinese).

Zhang, Wen-Xu, and An-Ping Pei

1997 Hun nan Li xian Meng xi Ba Shi Dang chu tu dao gu de yan jiu (Ancient rice from Bashidang Site, Mengxi in Lixian County, Hunan). Wen Wu (Cultural Relics) 1:36-41 (in Chinese).

ZHANG, XING-Yong

1991 Yun nan liang chu jiu shi qi mo qi zhi xin shi qi zao qi yi zhi (Report on the two Yunnan sites between late Palaeolithic and early Neolithic Age), in Ji Nian Huang Yan Dong Yi Zhi Fa Xian San Shi Zhou Nian Lun Wen Ji (Conference Papers on the Thirtieth Anniversary Discovery of Huangyandong Site): 109-111, ed. Fengkai Museum. Guangzhou: Guangdong Tourism Press (in Chinese).

ZHANG, XU-QIU

1992 Chang Jiang Zhong You Xin Shi Qi Shi Dai Wen Hua Gai Lun (Introduction of the Neolithic Cultures in Middle Yangtze River). Hubei: Hubei Science Technology Press (in Chinese).

Zhao, Chao-Hong, and Xiao-Hong Wu

2003 Zhong guo zao qi tao qi de fa xian ji xiang guan wen ti (The discovery of early pottery in China and its related problems), in Kao Gu Xue Yan Jiu (Archaeology Studies), Vol. 5 (I) : 98-100, ed. Department of Archaeology, Peking University. Beijing: Science Press (in Chinese).

ZHAO, HUI

1999 Zhu jiang san jiao zhou di qu ji he yin wen tao de chu xian he wen hua de fa zhan (The occurrences of geometric impressed pottery in Pearl River delta its cultural developments), in Rethink Cross-Century Archaeology in China, Vol. 1:221-250, ed. Xu Zho-yun and Zhang Zhong-pei. Hong Kong: The Commercial Press (in Chinese).

ZHAO, ZHI-JUN

1998 Middle Yangtze Region in China is one place where rice was domesticated: Phytolith evidence from the Diaotonghuan Cave, Northern Jiangxi. Antiquity 72(278):885897.

ZhaO, Zhi-Jun, Lie-Dan Lu, AND XIAN-Guo Fu

2005 Guang xi yong ning xian ding si shan yi zhi chu tu zhi xi shi de fen xi yu yan jiu (Analysis and study on the phytolith from Dingsishan, Yongning, Guangxi). Kao Gu (Archaeology) $11: 76-84$ (in Chinese).

Zhu, Cheng, Shi-Yong Yu, and Chun-Cheng Lu

1997 Chang Jiang san xia ji jiang han ping yuan di qu quan xin shi huan jing kao gu yu yi chang hong lao zai hai yan jiu (The study of Holocene environmental archaeology and extreme flood disaster in the Three Gorges of the Changjiang River and the Jianghan Plain). Di Li Xue Bao (Acta Geographica Sinica) 52(3):268-278 (in Chinese).

ZHU, Yan-Ping

2004 Guang yu zhong guo zai pei zhi wu qi yuan wen ti de tan tao (Study on the origins of cultivated plants in China), in Qing Zhu Zhang Zhong Pei Xian Sheng Qi Shi Sui Lun Wen Ji (A Festschrift in Honor of Professor Zhang Chung-pei on the Occasion of his Seventieth Anniversary): 21-36, ed. Research Center of Chinese Frontier Archaeology of Jilin University. Beijing: Science Press (in Chinese).

Zou, Hou-Ben, Jian-Xiang Gu, Min-Chang Li, Ling-Hua Tang, Jing-Long Ding, and Qin-De YAO

2000 Jiang su cao xie shan ma jia bang wen hua shui tian de fa xian (Findings in the paddies of Majiabang Culture at Caoxieshan, Jiangsu Province), in Dao Zuo Tao Qi He Du Shi De Qi Yuan (The Origins of Rice Agriculture, Pottery and Cities): 97-114, ed. Wen-ming Yan and Yoshinori Yasuda. Beijing: Cultural Relics Publishing House Press (in Chinese). 
Zou, Hou-XI

2003 Chong qing xia jiang di qu de xin shi qi wen hua (Neolithic cultures of Xia-Jiang Region, Chongqing), in Chong qing 2001 San Xia Wen Wu Bao Hu Xue Shu Yan Tao Hui Lun Wen Ji (Conference Papers on the Preservation of Cultural Relics in Three Gorges, Chongqing, 2001): 17-40, ed. Chongqing Cultural Relics Bureau. Beijing: Science Press (in Chinese).

\begin{abstract}
According to direct evidence from archaeology and supporting evidence from comparative linguistics, the Neolithic cultures of the Yangtze alluvial plain played a significant role in the origins of rice cultivation and agricultural populations in East and Southeast Asia. The ultimate results of these developments, according to many authorities, were the dispersals of Austroasiatic and Austronesian-speaking peoples into Mainland and Island Southeast Asia. New archaeological discoveries suggest that some of the earliest pottery in the world also occurred in southern China. Therefore, the historical significance of this region cannot be overlooked. This paper provides a brief review of cultural developments and settlement histories in southern China from the early Neolithic (c. 11,000-8000 B.C.) to the terminal Neolithic (2000 B.C.). Geographically, we examine the middle and lower Yangtze alluvial plain, the Lingnan (southern Nanling Mountains) and Fujian region, and the Yungui Plateau of southern China. Against the backdrop of the waxing and waning of Neolithic cultures in the Yangtze Valley we plot the spread of material culture, rice farming and animal domestication out of the Yangtze region to the Lingnan-Fujian region and the Yungui Plateau, and later into Taiwan and Southeast Asia. This study suggests that the origins of rice agriculture and the process of farming dispersal were more complicated than previously assumed. KeYwords: Neolithic, southern China, Yangtze alluvial plain, farming, migration, dispersal.
\end{abstract}

\title{
APPENDIX: ARCHAEOLOGICAL SITE NAMES USED IN THIS ARTICLE (IN ALPHABetical ORder, USing THE PINYIN SPELling)
}

A

Anhui

B

Badong

Baise

Baiyangcun

Baligang

Baoduncun culture

Baoshan

Baozitou

Bashidang

Beidaling

Beiyinyangying

C

Caoxieshan

Changyang

Chao Lake plain

Chengbeixi culture

Chengdu plain

Chengtoushan

Chenqiaocun

Chongqing

Cishan-Peiligang culture cong
安徽

巴东
百色
白羊村
八里岗
宝墩村文化
保山
豹子头
八十垱
北大岭
北阴阳营

草鞋山

长阳

巢湖平原

城背溪文化

成都平原

城头山

陈桥村

重庆

磁山一裴李岗文化 琮
D

Dabenkeng culture

Dadong

Daiziping assemblage

Datang culture

Daxi

Daoxian

Dawan culture

Dawenkou culture

Dayan

Dian Lake

Diaotonghuan

Dingsishan culture

Dongting Lake

Doupengpo culture

Duan

\section{大坌坑文化 \\ 大洞 \\ 岱子坪类型 \\ 大塘文化 \\ 大溪 \\ 道县 \\ 大湾文化 \\ 大汶口文化 \\ 大岩 \\ 滇池 \\ 吊桶环 \\ 顶蚛山文化 \\ 洞庭湖 \\ 斗篷坡文化 \\ 都安}

E

Erligang phase

Exi

二里岗文化阶段

F

Fanchengdui culture

Fangcheng

樊城堆文化

防城

反山

Fujian 福建 


\section{G}

Gan Valley

Gan-Bo region

Gaomiao culture

Gexinqiao

Guangdong

Guandukou

Guangfulin culture

Guangxi

Gui

Guilin

Guizhou

H

Han Valley

Hainan Island

hangtu

Hanshan

Hanzhong

Henan

Hejiacun

Hemudu

Hexian

Hoabinhian culture

Honghuatao

Huai River

Hubei

Hunan

\section{J}

Jiahu

Jiang-Zhe region

Jianghan plain

Jiangsu

Jianshi

Jigongshan

K

Keqiutou culture

Kuahuqiao

L

Li River

Liangzhu

Liaodong peninsula

Lijiacun

Lingnan (southern Nanling Mountains)

Lingnan facies of the Daxi culture

Lingjiatan

Liujiang Man

Lixian

Liyuzui

Longgu cave

Longshan cultures

Ludun remains

Lungshanoid hypothesis

赣江河谷
赣鄱地区
高庙文化
革新桥
广东
官渡口
广富林类型
广西
萬
桂林
贵州

汉水河谷

海南岛

夯土

含山

汉中

河南

何家村

河姆渡

和县

和平文化

红花套

淮河

湖北

湖南

賈湖

江浙地区

江汉平原

江苏

建始

鸡公山

蚵丘头文化

跨湖桥

澧水

良渚

辽东半岛

李家村

岭南

大溪文化岭南型

凌家滩

柳江人

澧县

鲤鱼嘴

龙骨洞

龙山文化

陆墩遗存

龙山形成期理论
M

Maba 马坝

Majiabang 马家浜

Majiayao culture 马家窑文化

Maludong cave 马鹿洞

Maoxian 茂县

Maqiao culture 马桥文化

Mengzi 蒙自

Miaoyan 庙岩

Mid-Han River region 汉水中游地区

Min River 闽江

$\mathbf{N}$

Nandang culture 南荡文化

Nanjing 南京

Nanling Mountains 南岭

Nanyang basin 南阳盆地

Ningzhen area 宁镇地区

$\mathbf{P}$

Penghu archipelago 澎湖群岛

Pengtoushan 彭头山

Pengtoushan-Zaoshi culture 彭头山-皇市文化

Poyang Lake plain 鄱阳湖平原

Q

Qiantang basin 钱塘江流域

Qinling Mountains 秦岭

Qujialing

Qujialing-Shijiahe culture

屈家岭

屈家岭-石家河文

化

$\mathbf{S}$

Sanxingcun 三星村

Shanbei culture 山背文化

Shandong 山东

Shang civilization 商代

Shangshan-Kuahuqiao cul- 上山-跨湖桥文化 ture

Shanxi

山西

Shijiahe culture 石家河文化

Shilaodun 史老墩

Shinianshan 拾年山

Shiweishan 石尾山

Shixia culture 石峡文化

Sichuan 四川

Songze 崧泽

southern China 中国南方

Suizao corridor 随疋走廊

Su-Wan region 苏皖平原区

\section{$\mathbf{T}$}

Tai Lake 太湖

Tangjiagang culture 汤家岗文化

Tangzigou 塘子沟

Tanshishan 县石山 


\begin{tabular}{|c|c|c|c|}
\hline Three Gorges & 三峡 & Yangtze River & 长江 \\
\hline \multirow[t]{2}{*}{ Two Lakes region } & 两湖地区 & Yaoshan & 瑶山 \\
\hline & & Yellow River & 黄河 \\
\hline $\mathbf{W}$ & & Yichang & 宜昌 \\
\hline Wangyoufang & 王油坊 & Yingde & 英德 \\
\hline Wannian & 万年 & Yingpanshan & 营盘山 \\
\hline Wei River & 渭水 & Yong River & 邑江 \\
\hline Wusaoling assemblage & 乌骚岭类型 & You River & 右江 \\
\hline \multirow[t]{2}{*}{ Wushan } & 巫山 & Yuan River & 沅水 \\
\hline & & Yuanmou & 元谋 \\
\hline & & Yuchanyan & 玉蟾岩 \\
\hline $\mathbf{X}$ & & Yun-Gui Region & 云贵地区 \\
\hline $\mathrm{Xi}$ basin & 西江流域 & Yungui plateau & 云贵高原 \\
\hline Xia-Jiang region & 峡江地区 & Yung? & $\begin{array}{l}\text { 厶则同尔 } \\
\text { 云南 }\end{array}$ \\
\hline Xianfan Valley & 襄樊谷地 & Yunnan & 云南 \\
\hline Xiang basin & 湘江流域 & Yunxian & 郧县 \\
\hline Xianrendong & 仙人洞 & Yuxi & 玉溪 \\
\hline Xiantouling culture & 咸头岭文化 & Yuxiping culture & 玉溪坪文化 \\
\hline Xiaojin & 晓锦 & 7 & \\
\hline Xiawanggang & 下王岗 & $\mathbf{Z}$ & \\
\hline Xichuan & 䉼川 & Zanmiao remains & 筸庙遗存 \\
\hline Xuejiagang & 薛家岗 & Zengpiyan & $\begin{array}{l}\text { 潧皮岩 } \\
\text { 张四墩遗存 }\end{array}$ \\
\hline & & Zhejiang & 浙江 \\
\hline $\mathbf{Y}$ & & Zhu (Pearl) River & 珠江 \\
\hline Yangjiawan & 杨家湾 & $\mathrm{Zi} \mathrm{basin}$ & 资水流域 \\
\hline Yangshao culture & 仰韶文化 & Ziyang & 资阳 \\
\hline Yangtze delta & 长江三角洲 & Zuo River & 左江 \\
\hline
\end{tabular}

